\title{
Litogeoquímica e geocronologia dos ortognaisses migmatíticos do Domo de Itabaiana, Sergipe: uma suíte do tipo tonalito, trondhjemito e granodiorito?
}

\author{
Lithogeochemistry and geochronology of the migmatitic orthogneisses from the \\ Itabaiana Dome, Sergipe, Brazil: a typical tonalite-trondhjemite-granodiorite suite?
}

\author{
Renato Carlos Vieira Santiago ${ }^{1,2}$, Angela Beatriz de Menezes Leal ${ }^{1,2}$, Moacyr Moura Marinho', \\ Roberto Max Argollo1, Johildo Salomão Figueiredo Barbosa ${ }^{1,2}$, Eduardo Reis Viana Rocha Júnior²,3 \\ ${ }^{1}$ Instituto de Geociências, Universidade Federal da Bahia - UFBA, Rua Barão de Jeremoabo, s/n, \\ Campus Universitário de Ondina, CEP 40170-020, Salvador, BA, BR (rcpetro86@yahoo.com.br; angelab@ufba.br; \\ mmm@ufba.br; robmax@ufba.br; johildo@cpgg.ufba.br) \\ ${ }^{2}$ Programa de Pós-Graduação em Geologia, Instituto de Geociências, Universidade Federal da Bahia - UFBA, Salvador, BA, BR \\ ${ }^{3}$ Departamento de Física da Terra e do Meio Ambiente, Instituto de Física, Universidade Federal da Bahia - UFBA, \\ Salvador, BA, BR (eduardo.junior@ufba.br)
}

Recebido em 10 de outubro de 2016; aceito em 27 de setembro de 2017

\begin{abstract}
Resumo
O Domo de Itabaiana encontra-se inserido no Domínio Vaza Barris da Faixa de Dobramentos Sergipana, no Estado de Sergipe. Está representado por um complexo gnáissico-migmatítico, constituído por ortognaisses migmatizados, com intercalações de níveis anfibolíticos. O conjunto foi retrabalhado e soerguido durante o processo de deformação Neoproterozoica dessa faixa. Estudos petrográficos revelam que os ortognaisses são de composição tonalítica a granodiorítica, por vezes com feições desde protomiloníticas a miloníticas. A litogeoquímica evidenciou um caráter sódico nessas rochas, as quais foram analisadas em dois grupos distintos, em relação aos seus padrões em ETR e teores de $\mathrm{K}_{2} \mathrm{O}$. Os litotipos com teores de $\mathrm{K}_{2} \mathrm{O}<2,5 \%$ compreendem termos da série cálcio-alcalina de baixo $\mathrm{K}$ a cálcio-alcalina normal, enquanto aqueles com teores de $\mathrm{K}_{2} \mathrm{O} \geq 2,5 \%$ compreendem termos posicionados na interface da série cálcio-alcalina normal com a série cálcio-alcalina de alto K. Os dois grupos possuem anomalias negativas de Th-U, Ta-Nb e Ti, além de baixos teores de Y, apresentando um padrão fortemente fracionado, com o enriquecimento em terras raras leves e empobrecimento em terras raras pesadas. Apenas um grupo apresenta anomalia positiva de Sr e concavidade nos espectros dos terras raras pesados, feições também típicas dos TTGs arqueanos. Sugere-se que ambos possuem afinidade com TTGs e que o grupo mais enriquecido em $\mathrm{K}_{2} \mathrm{O}$ sofreu algum tipo de participação crustal em sua gênese. As análises geocronológicas determinaram uma idade de $2729 \pm 12 \mathrm{Ma}$ (LA-ICP-MS), interpretada como idade de cristalização dos ortognaisses.
\end{abstract}

Palavras-chave: Domo de Itabaiana; Ortognaisses; TTGs arqueanos; Cálcio alcalina normal.

\begin{abstract}
The Itabaiana Dome is inserted in the Vaza Barris Domain of the Sergipano Belt, in the state of Sergipe, Brazil. It comprises an gneissicmigmatitic complex composed of migmatized orthogneisses, with interbedded amphibolite levels. The set was reworked and uplifted during the Neoproterozoic deformation process this range. Petrographic studies show that the orthogneisses are tonalite to granodiorite composition, with features from the protomylonitics to mylonitic. The lithogeochemistry shows a strong sodic characteristic of these rocks, which were analyzed in two different group, considering their rare-earth elements (REE)'s pattern and $\mathrm{K}_{2} \mathrm{O}$ content. The lithotypes with the contents of $\mathrm{K}_{2} \mathrm{O}<2,5 \%$ have a term of calcium alkaline series of low $\mathrm{K}$ to normal calcium alkaline. However, the ones with content $\mathrm{K}_{2} \mathrm{O} \geq 2.5 \%$ consist in placed terms in the interface of a normal calcium alkaline series, with a high $\mathrm{K}$ calcium alkaline series. The two groups pose a negative anomaly of Th-U, Ta-Nb and Ti with low content of Y. They exhibit a strong fractional pattern, with light rare earth enrichment and depletion of heavy rare earths. Only one group shows a positive anomaly of $\mathrm{Sr}$ and the spectrum concavity of heavy rare earths, which are typical features of the Archean tonalite-trondhjemite-granodiorite - Archean TTGs. It is suggested that both has affinity with TTGs and the group that is more enriched in $\mathrm{K}_{2} \mathrm{O}$ received a type of crustal participation in its gneiss. The geochronological analyses determined age of $2729 \pm 12 \mathrm{Ma}$ (LA-ICP-MS), which is translated as the age of the rock crystallization of orthogneisses.
\end{abstract}

Keywords: Itabaiana Dome; Orthogneisses; Archean TTG; Calc-alkaline normal. 


\section{INTRODUÇÃO}

O interesse no estudo das suítes tonalito, trondhjemito e granodiorito (TTG) decorre do fato de que cerca de $90 \%$ da crosta juvenil gerada entre 4,0 e 2,5 Ga é constituída de rochas pertencentes a essas suítes (Condie, 1993; Martin et al., 2005). As rochas que compõem essa crosta terrestre antiga pertencem aos complexos gnáissicos arqueanos, formados, principalmente, por TTGs, sendo que os trondhjemitos são as rochas predominantes (Barker, 1979). O Domo de Itabaiana, objeto de estudo, é um exemplo de complexo gnáissico-migmatítico com características compatíveis com as típicas suítes TTG arqueanas (Moyen e Martin, 2012). Está localizado na porção central do Estado de Sergipe, circundado por litotipos da Faixa de Dobramentos Sergipana, mais precisamente do domínio litoestratigráfico Vaza Barris.

Os primeiros trabalhos sobre o Domo de Itabaiana são da década de 1960. Humphrey e Allard (1969) dataram gnaisses do Domo de Simão Dias (o qual já se pensava ser cronocorrelato com o Domo de Itabaiana), determinando idade $\mathrm{Rb}-\mathrm{Sr}$ de rocha total de 2,5 Ga. Brito Neves et al. (1977) dividiram o embasamento da Faixa de Dobramento Neoproterozoica Sergipana em quatro domos: Jirau do Ponciano, Alto do Brejo, Itabaiana e Simão Dias, no intuito de tentar entender a evolução desses complexos gnáissico-migmatíticos. D'el Rey Silva $(1992,1995)$ admitiu que as deformações presentes no domo são cronocorrelatas àquelas presentes nos metassedimentos do Domínio Vaza Barris. Esses autores propuseram três fases de deformações, afetando ambas as unidades. Oliveira et al. (2010) determinaram uma idade U-Pb (Shrimp) de $2868 \pm 25$ Ma para o paleossoma do Domo de Simão Dias, que é interpretado como cronocorrelato ao Domo de Itabaiana. Santiago (2014) caracterizou petrograficamente os litotipos dessa unidade, como tratou os dados químicos de forma mais preliminar, sugerindo uma afinidade com as suítes TTG para essas rochas.

Este trabalho representa uma contribuição para os avanços na compreensão das associações TTG e da evolução magmática do Domo de Itabaiana, tendo como base estudos petrográficos, litogeoquímicos e geocronológicos.

\section{GEOLOGIA REGIONAL}

\section{A Faixa de Dobramentos Sergipana}

A Província Borborema está representada, no Estado de Sergipe, pela Faixa de Dobramentos Sergipana (Figura 1), situada entre o limite nordeste do Cráton do São Francisco e o Maciço Pernambuco-Alagoas. Os primeiros estudos atribuíram a sua formação à colisão entre o Cráton do Congo-São Francisco (CSF) e o maciço Pernambuco-Alagoas (PEAL), durante a Orogenia Brasiliana (Brito Neves, 1975; Davison e Santos, 1989). Essa faixa de dobramentos foi inicialmente interpretada como um geossinclinal típico (Humphrey e Allard, 1969; Silva Filho et al., 1978; Silva Filho e Brito Neves, 1979), depois como uma colagem de domínios tectono-estratigráficos ou microplacas (Santos et al., 1988; Davison e Santos, 1989), ou como um fold-thrust belt Neoproterozoico, resultante da inversão de uma margem passiva localizada na borda nordeste da antiga Placa São Francisco (D’el-Rey Silva, 1999). Santos et al. (1988) e Davison e Santos (1989) foram os primeiros a identificar compartimentos limitados por zonas de cisalhamento na Faixa de Dobramentos Sergipana. Mais recentemente, Oliveira et al. $(2010,2015)$ interpretaram a sua evolução a partir da quebra de um continente Paleoproterozoico, seguida por desenvolvimento de um arco continental e, posteriormente, estabelecendo-se, ao sul, como uma margem continental passiva, a qual foi invertida e colada durante a orogênese Brasiliana, em um ciclo completo de placa tectônica (Orógeno Sergipano).

A interpretação da Faixa Sergipana como uma colagem de domínios tectono-estratigráficos deve-se à dificuldade de se estabelecer a correlação estrutural e estratigráfica entre os seus vários seguimentos. Esses domínios representam diferentes níveis crustais, colocados lado a lado devido aos soerguimentos provocados pelas movimentações tectônicas compressivas e transcorrentes brasilianas, com vergência geral para SSW. Assim, foram identificados, de sul para norte: o Cráton do São Francisco; cobertura neoproterozoica que integra o Domínio Estância; o Domínio Vaza Barris; o Domínio Macururé; o Domínio Marancó; o Domínio Poço Redondo; e o Domínio Canindé. Posteriormente, D’el-Rey Silva (1995) e Santos et al. (1998) validaram essa divisão litoestratigráfica (Figura 2), caracterizando de forma mais explicita o Domínio Estância. Foram também esses autores que caracterizaram as descontinuidades estruturais profundas que limitam esses domínios como zonas de cisalhamento contracionais oblíquas de alto ângulo, sinistrais (Figura 2).

Os Domínios Estância e Vaza Barris são constituídos predominantemente por rochas sedimentares a metassedimentares. As condições de temperatura do metamorfismo aumentam de sul para norte, sob baixa a média pressão, desde a ausência de metamorfismo a fácies xisto verde no Domínio Estância, fácies xisto verde no Vaza Barris e, finalmente, fácies xisto verde a anfibolito no Macururé (Santos et al. 1988, 1998; Vaz Guedes, 2016), onde, segundo Oliveira et al. (2006, 2010), alcança condições de fácies granulito mais ao norte, já no Estado de Alagoas. A compartimentação litoestratigráfica desses domínios, a seguir apresentada (Figura 2), é aquela estabelecida por Santos et al. (1998). Da mesma forma, foi mantida a nomenclatura desses autores para as unidades dos diferentes domínios.

\section{MÉTODOS ANALÍTICOS}

Foram coletadas 23 amostras em perfis estratégicos de amostragem (Figura 3), as quais foram preparadas no Laboratório 
de Preparação de Amostras do Instituto de Geociências da Universidade Federal da Bahia (UFBA) para confecção de lâminas delgadas. Estas foram descritas com o auxílio do microscópio petrográfico Carl Zeiss Axio Scope.A1 e do programa de geração de imagem Axion Vision, no Laboratório de Física Nuclear Aplicada. A análise modal foi estimada pelo método da visada (moda por visada), com a média a partir da análise de 10 campos de vista não superpostos.

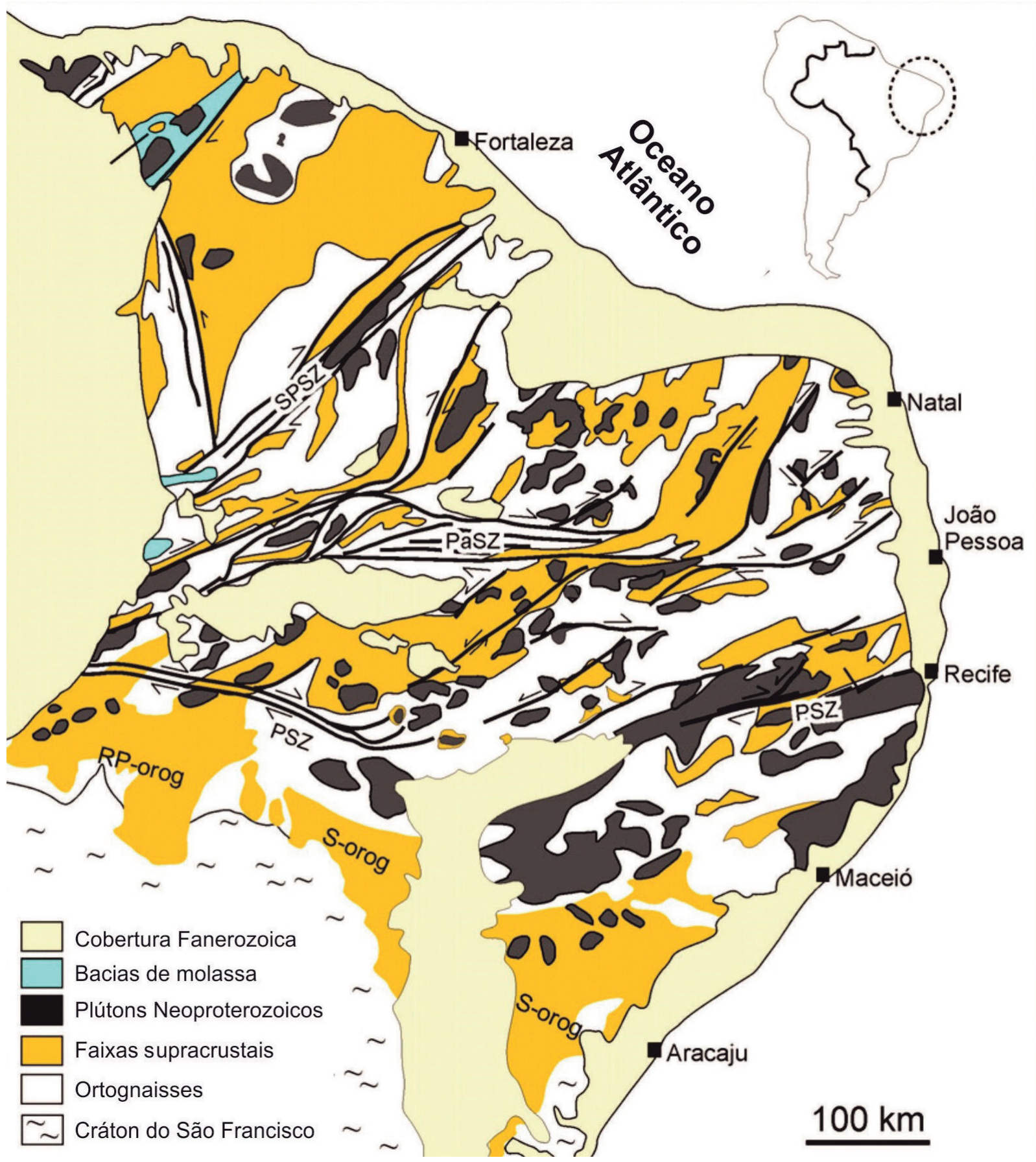

Fonte: Oliveira et al. (2015).

PSZ, PaSZ e SPSZ representam as principais zonas de cisalhamento: Pernambuco, Patos e Sobral-Pedro Segundo, respectivamente. RP-orog é o Orógeno Riacho do Pontal.

Figura 1. A Província Borborema mostrando a localização da Faixa Sergipana (orógeno Sergipano - S-orog) no sul (adaptado de Neves et al., 2009 apud Oliveira et al., 2015). 
A preparação e a análise litogeoquímica das 20 amostras foram feitas no laboratório ACME Analytical Laboratories e incluiu a britagem e a pulverização das amostras seguindo os padrões de qualidade do referido laboratório.

Os elementos maiores foram determinados por Espectrometria de Emissão Ótica com Plasma Indutivamente Acoplado (ICP-OES), e os traço e terras raras, por Espectrometria de Massa com Plasma Indutivamente Acoplado (ICP-MS). O pacote de serviço solicitado foi o Group 4A e 4B. Os limites de detecção variam de 0,04 a $0,01 \%$ para os elementos maiores e de 1 a $0,01 \mathrm{ppm}$ para os elementos-traço e ETR. Os valores de Perda ao Fogo foram determinados por calcinação em temperaturas da ordem de $1.000^{\circ} \mathrm{C}$, em que se pesa a amostra antes e depois do procedimento, a fim de obter os valores de perda. A determinação de $\mathrm{FeO}$ foi feita pelo método de titulometria por oxirredução.

Os dados obtidos foram tratados usando o software GCDkit 3.0 (Janoušek et al., 2011), gerando gráficos e diagramas de elementos maiores, traços e terras raras, os quais ajudaram a interpretar os resultados químicos obtidos.
A preparação inicial da amostra para datação U-Pb em zircão foi realizada no Laboratório de Isótopos Radiogênicos (LAIR) da Universidade Federal de Ouro Preto (UFOP), pelo método tradicional de britagem, moagem, concentração dos minerais pesados por bateia e separação em líquidos pesados. Os cristais individuais de zircão foram selecionados manualmente usando uma lupa binocular. Os grãos foram montados em resina epoxy, lixados, polidos e fotografados. Imagens via catodoluminescência (CL) e elétrons retroespalhados (BSE) foram obtidas com o uso de um microscópio eletrônico de varredura JEOL 6510. A metodologia utilizada para obtenção das idades $\mathrm{U}-\mathrm{Pb}$ em minerais de zircão seguiu os procedimentos analíticos descritos em Farina et al. (2015) e Takenaka et al. (2015).

Foram feitas análises isotópicas de U-Pb em 18 zircões, correspondendo a um total de 23 análises. Tais medidas foram efetuadas por meio da técnica de ablação com laser acoplada a um espectrômetro de massa com fonte de plasma indutivamente acoplado (, Laser Ablation Inductively Coupled Plasma Mass Spectrometry — LA-ICP-MS) do tipo Thermo-FinniganÒ ELEMENT-2

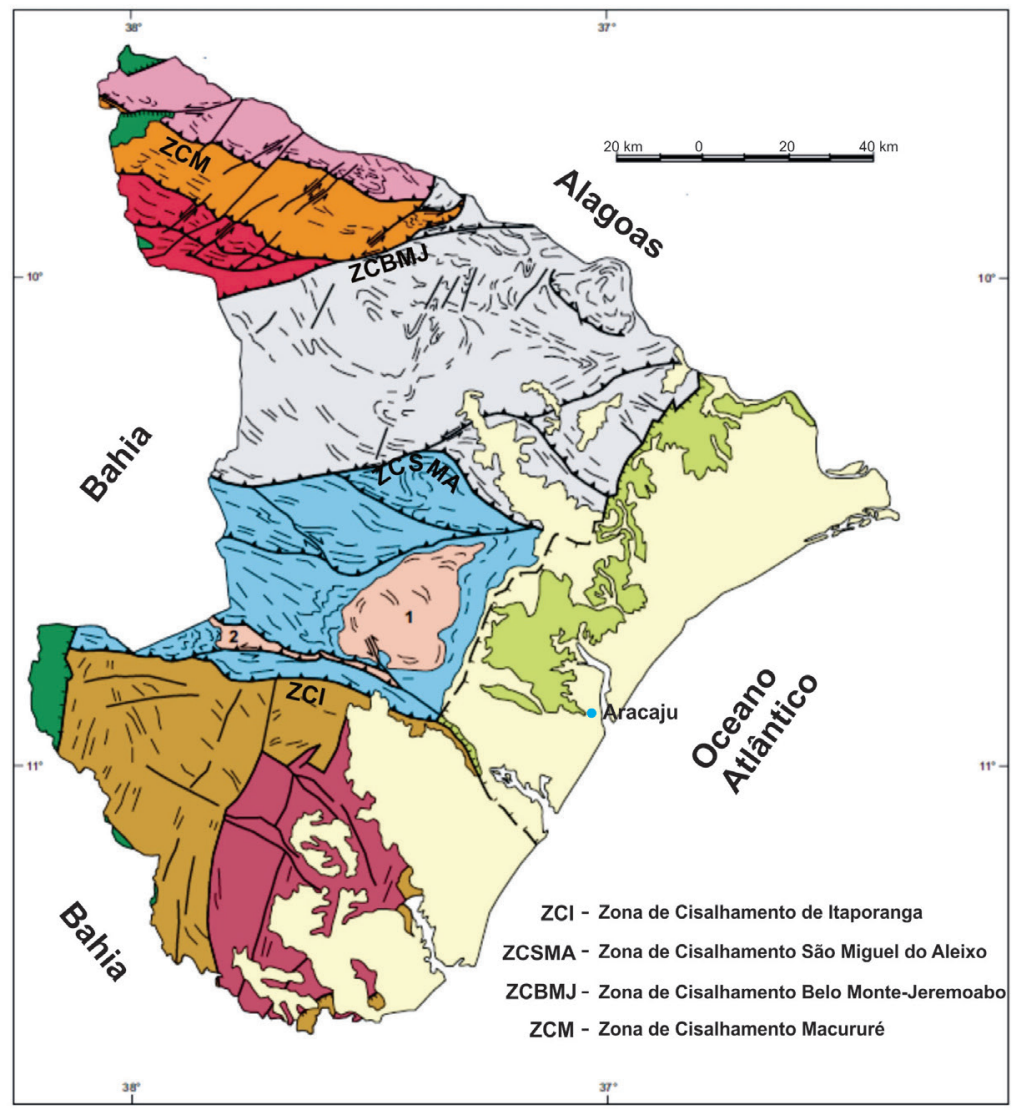

\section{Formações superficiais}

Bacias sedimentares

Bacia de Sergipe

Bacia de Tucano

Faixa de dobramentos sergipana

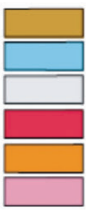

Domínio Estância

Domínio Vaza-Barris

Domínio Macururé

Domínio Marancó

Domínio Macururé

Domínio Marancó

Embasamento gnaissico

Cráton do São Francisco

Domos de Itabaina (1) e Simão Dias (2)

Alinhamentos estruturais
Contato definido
Falha extensional
Falha ou zona de cisalhamento
$-\quad \begin{aligned} & \text { Falha ou zona de cisalhamento transcorrent } \\ & \text { sinistral }\end{aligned}$
$\begin{aligned} & \text { Falha ou zona de cisalhamento transcorrent } \\ & \text { dextral }\end{aligned}$
$\begin{aligned} & \text { Falha ou zona de cisalhamento contracional } \\ & \text { Falha ou zona de cisalhamento contracional } \\ & \text { com componente transcorrente sinistral }\end{aligned}$

Fonte: adaptado de Santos et al. (1998).

Figura 2. Esboço tectono-estratigráfico do Estado de Sergipe. 
sector field no LAIR da UFOP. Foi utilizado um sistema de laser CETAC LXC - 213 G2. O laser foi configurado para produzir uma densidade energética de $\sim 8 \mathrm{~J} / \mathrm{cm}^{2} \mathrm{em}$ uma frequência de $10 \mathrm{~Hz}$, provocando furos nos grãos de zircão com diâmetro de $20 \mathrm{~mm}$ e profundidade de $15 \mathrm{a}$ $20 \mathrm{~mm}$. Os dados foram adquiridos no modo peak jumping durante 20 segundos de background, seguidos por 20 segundos de ablação do zircão. A correção do $\mathrm{Pb}$ comum foi baseada no modelo de composição de $\mathrm{Pb}$ proposto por Stacey e Kramers (1975). O fracionamento elementar induzido pelo laser e a discriminação instrumental de massa foram normalizados pelo zircão de referência GJ-1 (608 $\pm 1 \mathrm{Ma}$; Jackson et al., 2004), o qual foi analisado concomitantemente com as amostras, a fim de ambas possuírem as mesmas condições. Como padrão secundário, foi utilizado o zircão Plešovice (337.1 $\pm 0.4 \mathrm{Ma}$; Sláma et al., 2008). Os dados de sinal de tempo resolvido foram processados usando o pacote do software Glitter (Van Achterbergh et al., 2001) e os diagramas de distribuição de idades foram construídos com o uso de uma extensão do Excel denominada Isoplot (Ludwig, 2003).

\section{GEOLOGIA LOCAL}

\section{O Domo de Itabaiana}

O Domo de Itabaiana situa-se na porção central do Estado de Sergipe, circundado por litotipos da Faixa de Dobramentos Sergipana, mais precisamente do domínio litoestratigráfico Vaza Barris. Contornando a periferia do Domo de Itabaiana (Figura 3), encontra-se a Formação Itabaiana, que está na base do Grupo Miaba, a qual é caracterizada por uma sequência clástica bem típica, predominantemente de granulação grossa, composta principalmente de quartzitos puros, metaconglomerados, metaquartzarenitos, por vezes xistosos, com metapelitos subordinados, tipo filitos ou xistos.

A evolução desse compartimento rochoso começou a ser estudada a partir de 1969 por Humphrey e Allard, quando ele foi associado a uma estrutura oriunda de um processo de interferência de dobras. Daí especulou-se um processo de elevação associado a diapirismo, dobras por nappes (D'elRey Silva, 1994) ou "metamorphic core complex" produzidos por exumação extensional local, durante a inversão e
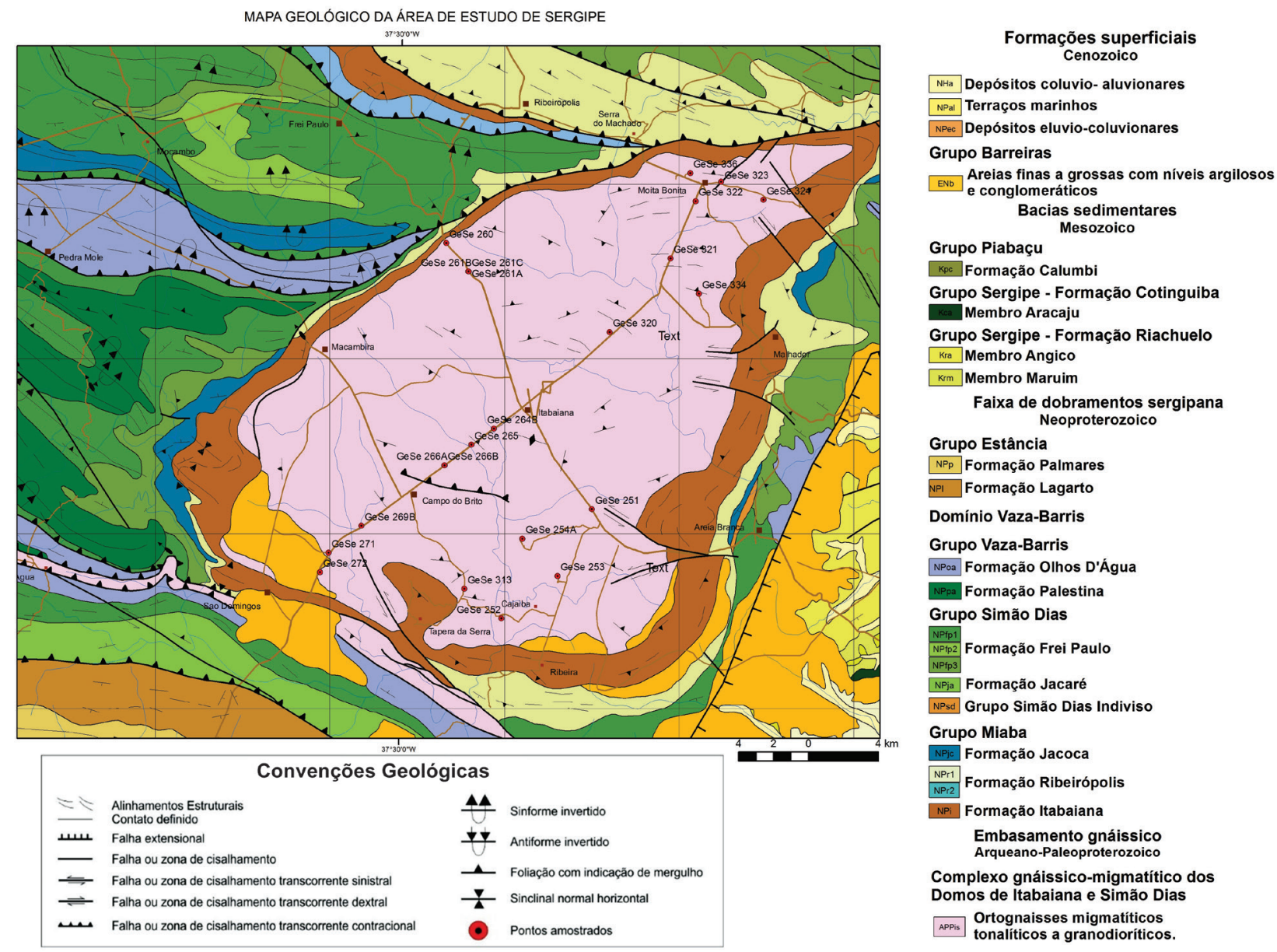

Fonte: adaptado de GEOTERM-NE (2010).

Figura 3. Recorte da área de estudo do mapa geológico de Sergipe. 
o fechamento das megasequências sedimentares, não existindo uma história consensual sobre a sua evolução.

\section{Aspectos de campo e petrográficos}

O complexo gnáissico-migmatítico do Domo de Itabaiana é composto basicamente de ortognaisses (Santos et al., 1998). Com raras intercalações anfibolíticas, esses ortognaisses não raramente exibem feições migmatíticas, refletindo vários estágios de anatexia, além de estarem, por vezes, milonitizados. Essas rochas encontram-se expostas em lajedos (Figuras 4A e 4B), cortes de estrada (Figura 4C), afloramentos de leito de rio, ou em pedreiras instaladas em proximidades de diferentes municípios (Figura 4D).

O estudo petrográfico de 23 lâminas dos gnaisses evidenciou uma forte segregação dos seus minerais máficos em relação aos agregados quartzo-feldspáticos, originando, assim, bandas mais félsicas e mais máficas, alternadas entre si. Essas rochas podem ser classificadas como faneríticas fina a média, inequigranulares seriadas no geral. As principais microestruturas encontradas são: porfiroclástica - representada por cristais de microclíneo e plagioclásio, envoltos por matriz mais fina, cominuída (Figuras 5A e 5B); granolepidoblástica - representada por agregado poligonal de quartzo e feldspato, associado a palhetas orientadas de biotita (Figuras 5C e 5D); milonítica - gerada por processos de cominuição da rocha; e augen - conferida pelos porfiroclastos em formas lenticulares (Figuras 5A e 5B).

Os protólitos foram classificados segundo proporções modais obtidas pelo método de visada e os valores foram plotados no diagrama QAP de Streckeisen (1976), resultando em tonalitos e granodioritos, com apenas duas amostras classificadas como monzogranitos (Figura 6). Essas rochas são compostas por plagioclásio (15 a 69\%), quartzo (15 a $28 \%$ ), K-feldspato (0 a 43\%), biotita (0 a 7\%), hornblenda $(0$ a $20 \%)$, clorita ( 0 a $3 \%)$, epídoto $(0$ a $5 \%)$, granada ( 0 a $3 \%)$, titanita (0 a $2 \%$ ) e opacos ( 0 a $2 \%$ ), além de apatita (traço) e zircão (traço) (Tabela 1).

Os níveis anfibolíticos (Figuras 4E, 5E e 5F) ocorrem em rochas de coloração verde-escuro a castanho-escuro, com porções acinzentadas, geralmente constituídas de cristais orientados de hornblenda, ou actinolita, com cerca de 2,0 mm de diâmetro, exibindo uma fraca lineação. Essas rochas são compostas por anfibólio (35 a 55\%), plagioclásio (28 a 40\%), granada (5 a $25 \%$ ), minerais opacos (2\%), além de minerais secundários ou de aporte hidrotermal, como quartzo e titanita (Tabela 1). No geral, essas rochas são faneríticas, de granulação fina a média, inequigranulares. Apresentam uma textura granonematoblástica conferida pelo agregado poligonal entre plagioclásio e anfibólio, este último aparecendo em cristais estirados segundo uma orientação preferencial, ambos associados à granada (Figura $5 \mathrm{E}$ ). Ocorre intercrescimento simplectítico (Figura 5F) entre plagioclásio, granada e anfibólio verde (hornblenda).

\section{LITOGEOQUÍMICA}

Foram analisadas 20 amostras dentre as estudadas na petrografia, sendo 18 dos ortognaisses e 2 de rochas anfibolíticas. Foi realizado um estudo com base em dados referentes a elementos maiores, traço e terras raras (Tabela 2). Com a utilização dessas análises foi possível caracterizar a natureza dos ortognaisses do Domo de Itabaiana, definindo também a sua afinidade magmática. As rochas ortognáissicas foram agrupadas em dois conjuntos, em função dos teores de $\mathrm{K}_{2} \mathrm{O}$ e padrões de ETR: Tipo I, caracterizado por $\mathrm{K}_{2} \mathrm{O}<2,5$ e espectros de ETR divergentes a partir do La; Tipo II, caracterizado por $\mathrm{K}_{2} \mathrm{O} \geq 2,5$ e espectros de ETR paralelos. Essas características independem do grau de deformação. As rochas anfibolíticas foram tratadas com os ortognaisses, sob a conjectura de serem termos menos diferenciados.

\section{Elementos maiores}

De acordo com os dados químicos apresentados na Tabela 2, os ortognaisses do Domo de Itabaiana mostram para os teores de $\mathrm{SiO}_{2}, \mathrm{Al}_{2} \mathrm{O}_{3}$ e razões $\mathrm{K}_{2} \mathrm{O} / \mathrm{Na}_{2} \mathrm{O}$, os seguintes valores para o Tipo I: $\mathrm{SiO}_{2}$ entre 64 e $74 \%, \mathrm{Al}_{2} \mathrm{O}_{3}$ entre 15,02 e 16,89\% e razões $\mathrm{K}_{2} \mathrm{O} / \mathrm{Na}_{2} \mathrm{O}$ entre 0,08 e 0,39. Para o Tipo II: $\mathrm{SiO}_{2}$ entre 70,59 e $73,51 \%, \mathrm{Al}_{2} \mathrm{O}_{3}$ entre 14,66 e $15,85 \%$ e razões $\mathrm{K}_{2} \mathrm{O} / \mathrm{Na}_{2} \mathrm{O}$ entre 0,58 e 0,71 . O índice de saturação em alumina $(\mathrm{A} / \mathrm{CNK})$ encontra-se geralmente em torno de 1,0 , para ambos os conjuntos, caracterizando essas rochas na interface metaluminosa/peraluminosa (Figura 7A). No entanto, as rochas ortognáissicas do Tipo II apresentam caráter mais peraluminoso, com apenas uma amostra (GESE-321) com tendência a metaluminosa. $\mathrm{O}$ diagrama $\mathrm{SiO}_{2}$ versus $\mathrm{K}_{2} \mathrm{O}$ (Figura 7B) mostra uma separação bem evidente dos dois grupos. Os ortognaisses do Tipo I são mais empobrecidos nos teores de $\mathrm{K}_{2} \mathrm{O}(<2,5 \%)$, classificando-os entre a série de baixo $\mathrm{K}$ e cálcio alcalina normal, enquanto os ortognaisses do Tipo II apresentam teores de $\mathrm{K} \geq 2,5 \%$, classificando-os entre as séries cálcio alcalina normal e alto K. Nesse diagrama, as amostras de rochas anfibolíticas se posicionam no campo cálcio-alcalino normal, sugerindo a possibilidade de representarem termos menos diferenciados do Tipo I.

No diagrama An-Ab-Or de O'Connor (1965) (Figura 8A), pode-se verificar que todas as amostras do grupo Tipo I situam-se nos campos trondhjemito e tonalito, enquanto as amostras do grupo Tipo II situam-se quase que totalmente no campo do trondhjemito, com certa proximidade ao campo do granito e leve tendência ao granodiorito. Essa posição das amostras do Tipo I pode indicar que pelo menos esse grupo pertença à série dos trondhjemitos.

No diagrama Na-K-Ca de Barker e Arth (1976) (Figura 8B), as amostras do Tipo I exibem afinidade trondhjemítica típica com os TTGs arqueanos, caracterizada principalmente pelo enriquecimento em sódio que mostra 

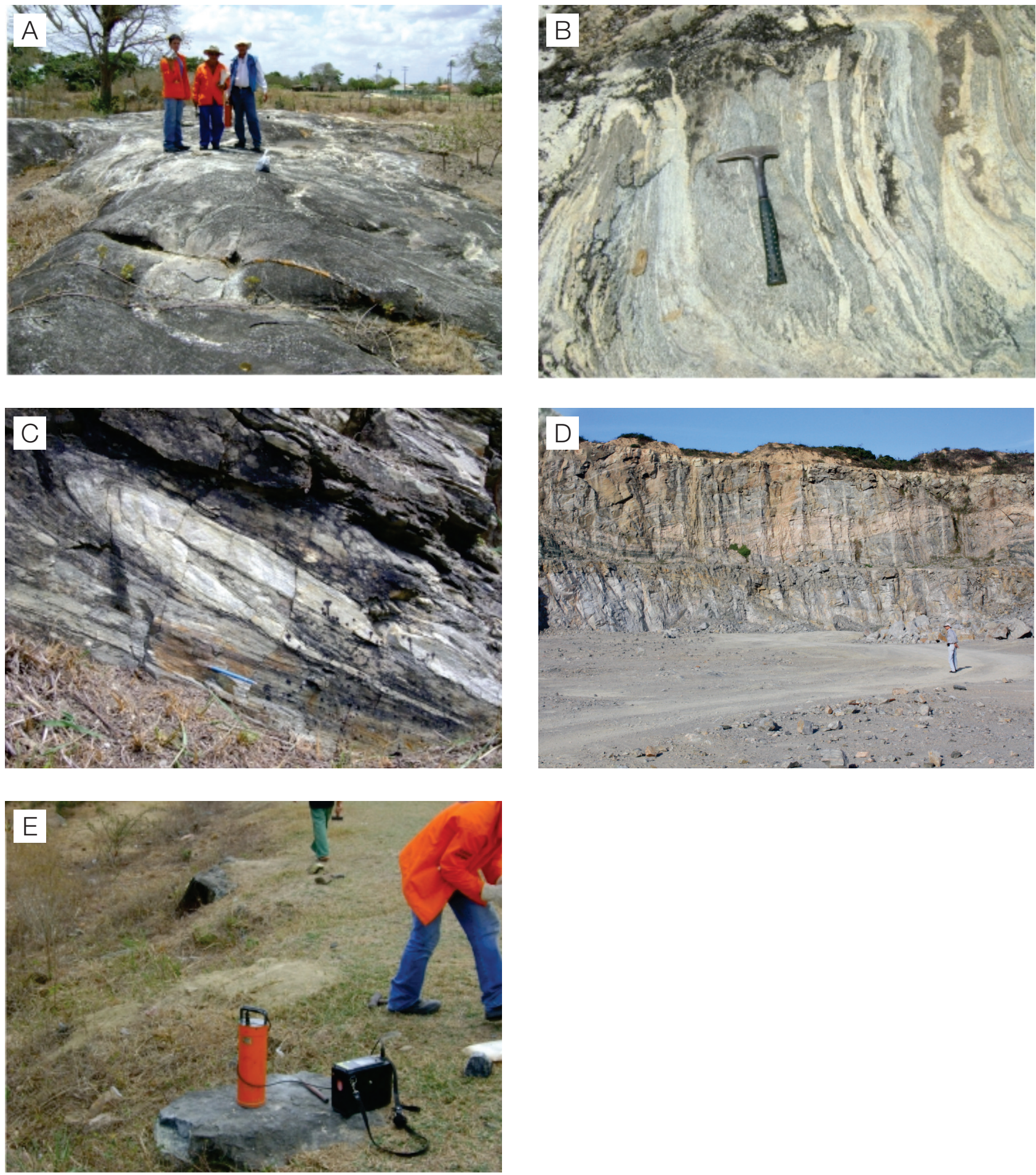

Figura 4. (A) Visão geral do lajedo na margem N da SE-240, no trecho entre Moita Bonita e o Povoado de Serra do Machado. Ponto GESE 323. Coordenadas: 0682404/8830157. (B) Visão geral do caráter migmatítico (tipo metatexito) dos ortognaisses. Ponto GESE 336. Coordenadas: 0680637/8830642. (C) Dobra reclinada, intrafolial, sem raiz (flanco rompido) com indicação de movimentação tectônica para SW em gnaisse bandado. Corte na rodovia Lagarto - Itabaiana. Ponto GESE 266A. Coordenadas: 0666566/8813932. (D) Dobra recumbente em escala hectométrica na frente de lavra da Pedreira Rio das Pedras, a SSW da cidade de Itabaiana e SW do povoado de Cajaíba. Ponto GESE 252. Coordenadas: 0669816/8805164. (E) Aspecto geral dos blocos rolados dos níveis anfibolíticos. Ponto GESE 334. Coordenadas: 0681140/8823743. 

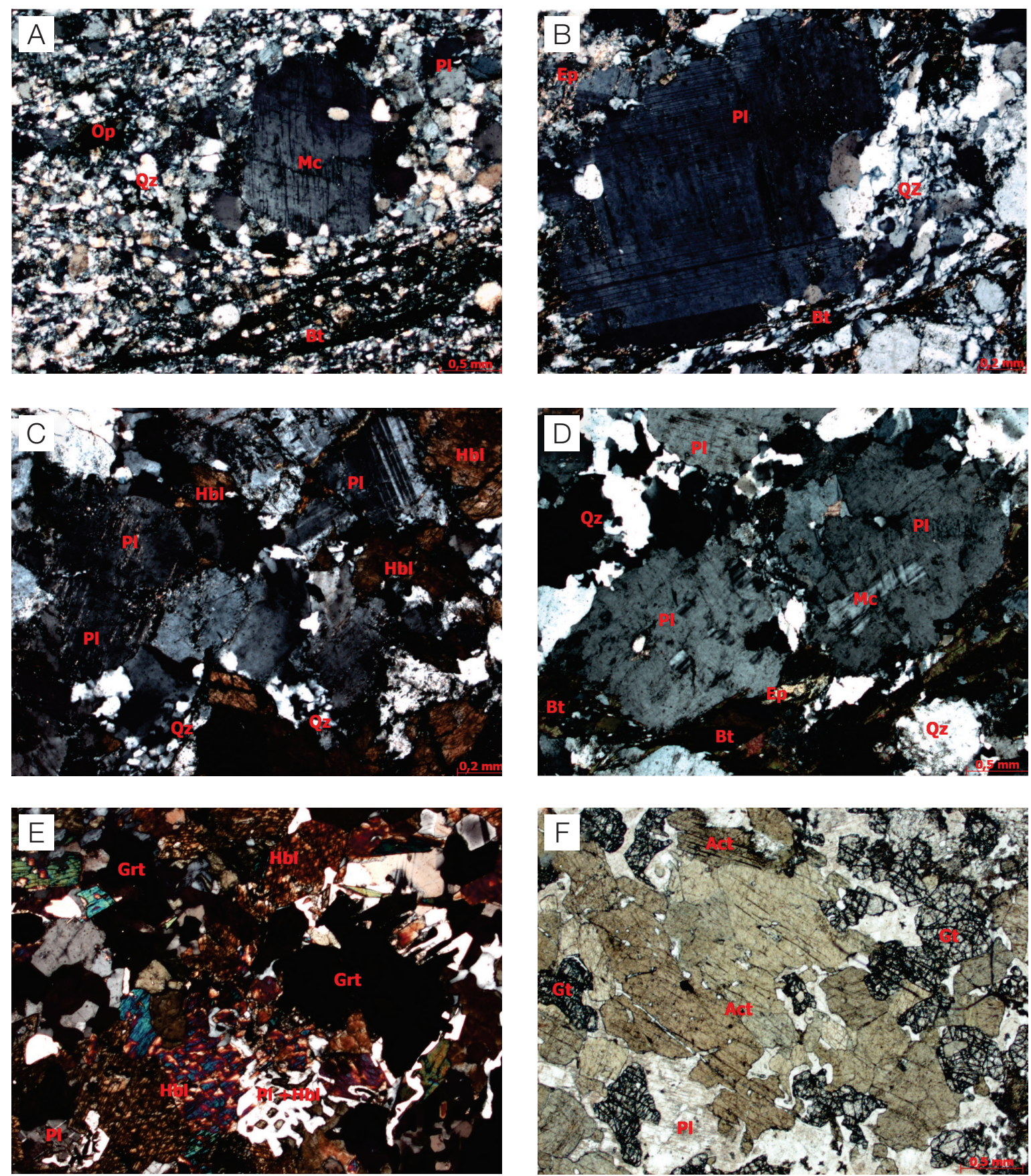

Figura 5. (A) Porfiroclasto fusiforme, estirado e orientado de microclínio pertítico (Mc), em meio a uma matriz esmigalhada de mesma composição, com quartzo (Qz) preenchendo as fraturas que cortam a rocha. Amostra GESE 252. Nx. Aumento de 25x. (B) Detalhe do porfiroclasto fusiforme de plagioclásio (PI) exibindo bordas microquebradas, em contato interlobado a suturado com matriz quartzo-feldspática, preservando a geminação albita, de forma complexa. Quartzo (Qz) ocorre em contatos ameboides entre si e palhetas de biotita (Bt) encontram-se retorcidas, segundo a foliação principal da rocha. Amostra GESE 254. Nx. Aumento de 50x. (C) Cristais tabulares de plagioclásio (PI), alguns geminados em albita simples, com os interstícios preenchidos por agregado poligonal, esmigalhado, de quartzo $(\mathrm{Qz})$ e por agregados de cristais, de irregulares a subédricos, de hornblenda (Hbl). Amostra GESE 313. Nx. Aumento de 50x. (D) Intercrescimento de microclínio (Mc) em cristais de plagioclásio (PI), conferindo uma textura simplectítica (antipertítica) à rocha. Amostra GESE-266-B. Nx. Aumento de 25x. (E) Cristais prismáticos a poligonais de actinolita (Act), de cor verde cana, em contatos retos a irregulares com cristais de granada (Grt), bastante fraturados, e plagioclásio. Amostra GESE- 261C. Lp. Aumento de 25x. (F) Cristais subdiomórficos a xenomórficos de granada (Grt) e hornblenda ( $\mathrm{Hbl})$, em contatos retos a irregulares entre si, com plagioclásio (Pl), em intercrescimento simplectítico. Amostra GESE-334. Nx. Aumento de 25x. Abreviações dos minerais segundo Siivola e Schmid (2007). 
esse grupo. As amostras do grupo Tipo II também demonstram certa tendência ao campo de afinidade TTG, com maior enriquecimento em $\mathrm{K}$.

Com base nos diagramas de Harker (1909), $\mathrm{SiO}_{2}$ versus elementos maiores (Figura 9), percebe-se que os teores de $\mathrm{TiO}_{2}, \mathrm{Al}_{2} \mathrm{O}_{3}, \mathrm{MgO}, \mathrm{CaO}, \mathrm{P}_{2} \mathrm{O}_{5}$ e $\mathrm{Fe}_{2} \mathrm{O}_{3 \mathrm{t}}$ decrescem com a diferenciação, evidenciando o caráter compatível com o sólido desses elementos. Contrariamente, $\mathrm{K}_{2} \mathrm{O}$ apresenta um caráter incompatível, resistindo na parte líquida durante a diferenciação magmática. Esse comportamento mostra que o sólido fracionado era rico em $\mathrm{TiO}_{2}, \mathrm{Al}_{2} \mathrm{O}_{3}, \mathrm{MgO}, \mathrm{CaO}, \mathrm{P}_{2} \mathrm{O}_{5}$ e $\mathrm{Fe}_{2} \mathrm{O}_{3(t)}$ e pobre em $\mathrm{K}_{2} \mathrm{O}$. Pode-se, então, sugerir como assembleia mineral mais provável para seu sólido, uma mistura com presença de hornblenda, plagioclásio e opacos, e ausência de biotita e feldspato potássico. Verifica-se que, na maioria dos diagramas, as rochas anfibolíticas posicionam-se nos trends dos ortognaisses, especialmente naqueles do Tipo I, exceto para $\mathrm{Al}_{2} \mathrm{O}_{3}, \mathrm{P}_{2} \mathrm{O}_{5}$ e $\mathrm{K}_{2} \mathrm{O}$, que não mostram uma perfeita correlação evolutiva com os ortognaisses.

Podemos assim concluir, com base nas características dos elementos maiores propostos por Martin (1994) e Moyen e Martin (2012), como índice de alumina-saturação em torno de 1 (Tipo I: 0,9 a 1,13; Tipo II: 0,97 a 1,11), teores de sílica acima de $65 \%$ (Tipo I: 63,25 a 72,14; Tipo II: 70,59 a 73,61) e de $\mathrm{Al}_{2} \mathrm{O}_{3}$ maiores do que $15 \%$ (Tipo I: 15,02 a 16,76; Tipo II: 14,94 a 15,85), baixas razões $\mathrm{K}_{2} \mathrm{O} /$ $\mathrm{Na}_{2} \mathrm{O}$, somatórios $\mathrm{TiO}_{2}+\mathrm{Fe}_{2} \mathrm{O}_{3} \mathrm{t}+\mathrm{MgO}+\mathrm{Mn}$ inferiores ou próximos a 5\% (as amostras GESE 313, 336 e 266B fogem ao padrão) e inferiores a 3\% no Tipo 2 (apenas a amostra GESE 321 foge ao padrão), que ambos os grupos possuem

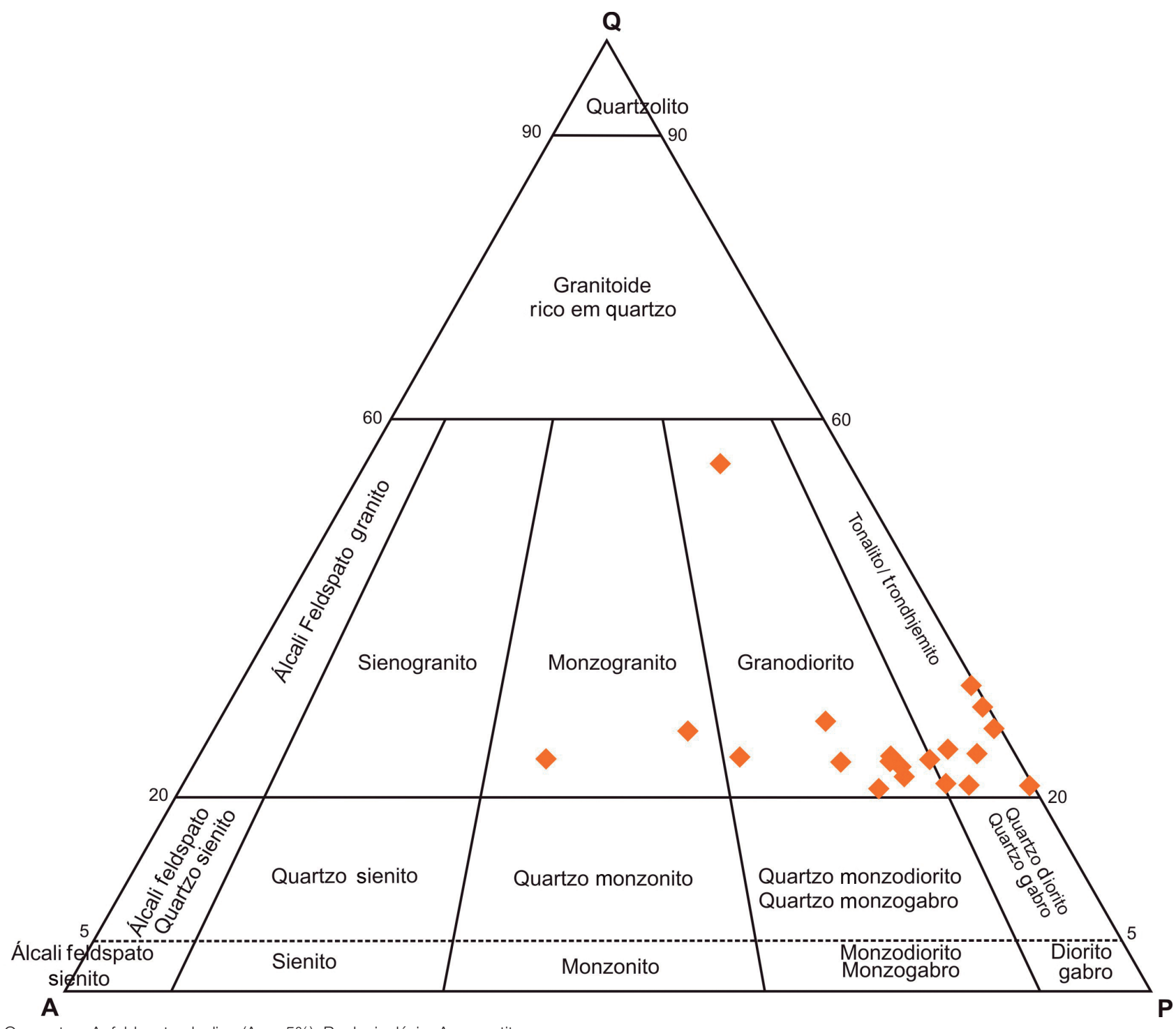

Q: quartzo; A: feldspato alcalino (An < 5\%); P: plagioclásio; An: anortita.

Figura 6. Diagrama QAP modal (Streckeisen, 1976) para as rochas ortognáissicas do Domo de Itabaiana. 
Tabela 1. Tabela com composição modal dos ortognaisses e dos níveis anfibolíticos do Domo de Itabaiana. Abreviação dos minerais segundo Siivola e Schmid (2007).

\begin{tabular}{|c|c|c|c|c|c|c|c|c|c|c|c|c|c|c|c|c|c|c|}
\hline \multirow{2}{*}{$\begin{array}{l}\text { Grupo de } \\
\text { amostras }\end{array}$} & \multirow{2}{*}{ Amostra } & \multirow{2}{*}{$\begin{array}{c}\text { Classificação } \\
\text { petrográfica (Q-A-P) } \\
\text { (Streckeisen, 1976) }\end{array}$} & \multicolumn{16}{|c|}{ Minerais (\%) } \\
\hline & & & $\mathrm{PI}$ & $Q z$ & Mc & Or & Fsp & Op & $\mathrm{Bt}$ & $\mathrm{Hbl}$ & $\mathrm{Di}$ & Act & Ap & $\mathrm{Cl}$ & Ep & Grt 1 & $\operatorname{Ttn} 2$ & $\mathrm{Zr}$ \\
\hline \multirow{21}{*}{ 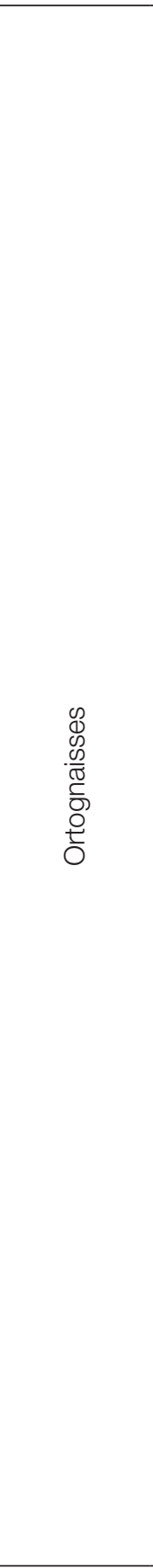 } & & Biotita augen ortognaisse & & & & & & & & & & & & & & & & \\
\hline & GESE 251 & & 45 & 22 & 25 & - & - & 1 & 3 & - & - & - & - & 3 & 1 & - & - & - \\
\hline & GESE 252 & $\begin{array}{l}\text { Ortognaisse granodiorítico } \\
\text { com biotita e epídoto } \\
\text { (milonítico) } \\
\text { Biotita ortognaisse }\end{array}$ & 15 & 25 & 5 & - & 43 & 2 & 3 & - & - & - & $\operatorname{tr}$ & 2 & 3 & - & 2 & $\operatorname{tr}$ \\
\hline & GESE 254-A & $\begin{array}{l}\text { tonalítico com titanita } \\
\text { (protomilonítico ) } \\
\text { Biotita epídoto augen }\end{array}$ & 62 & 22 & 05 & - & - & 1 & 5 & - & - & - & $\operatorname{tr}$ & - & 3 & - & 2 & $\operatorname{tr}$ \\
\hline & GESE 260 & $\begin{array}{c}\text { monzogranito com titanita } \\
\text { (milonítico) } \\
\text { Biotita ortognaisse }\end{array}$ & 30 & 18 & 19 & 20 & - & 2 & 5 & - & - & - & - & - & 5 & - & 1 & - \\
\hline & GESE 261-A & $\begin{array}{l}\text { tonalítico a granodiorítico } \\
\text { (protomilonítico) }\end{array}$ & 60 & 21 & 10 & - & - & - & 4 & - & - & - & $\operatorname{tr}$ & 3 & 1 & - & 1 & $\operatorname{tr}$ \\
\hline & GESE 261-B & $\begin{array}{c}\text { Biotita ortognaisse } \\
\text { tonalítico (protomilonítico) } \\
\text { Biotita ortognaisse }\end{array}$ & 69 & 18 & 5 & - & - & - & 3 & - & - & - & $\operatorname{tr}$ & 3 & 1 & - & 1 & $\operatorname{tr}$ \\
\hline & GESE 269-B & $\begin{array}{l}\text { tonalítico a granodiorítico } \\
\text { (protomilonítico) }\end{array}$ & 61 & 20 & 10 & - & - & - & 5 & - & - & - & $\operatorname{tr}$ & - & 1 & 3 & - & $\operatorname{tr}$ \\
\hline & GESE 271 & $\begin{array}{l}\text { Biotita ortognaisse } \\
\text { tonalítico (milonítico) } \\
\text { Hornblenda-biotita }\end{array}$ & 63 & 22 & 7 & - & - & $\operatorname{tr}$ & 5 & - & - & - & $\operatorname{tr}$ & - & 3 & - & - & $\operatorname{tr}$ \\
\hline & GESE 272 & $\begin{array}{l}\text { ortognaisse tonalítico } \\
\text { (protomilonítico) } \\
\text { Hornblenda ortognaisse }\end{array}$ & 58 & 21 & 10 & - & - & 1 & 5 & 3 & - & - & & - & 1 & - & 1 & - \\
\hline & GESE 313 & $\begin{array}{l}\text { tonalítico com granada } \\
\text { (milonítico) }\end{array}$ & 60 & 15 & - & - & - & 2 & - & 20 & - & - & $\operatorname{tr}$ & - & - & 3 & - & $\operatorname{tr}$ \\
\hline & GESE 253 & $\begin{array}{l}\text { Biotita ortognaisse } \\
\text { tonalítico }\end{array}$ & 69 & 18 & 7 & - & - & 1 & 5 & - & - & - & - & - & - & - & - & - \\
\hline & GESE 264-A & $\begin{array}{l}\text { Hornblenda ortognaisse } \\
\text { tonalítico com granada }\end{array}$ & 59 & 27 & - & - & - & 1 & & 10 & - & - & - & - & - & 3 & - & - \\
\hline & GESE 265 & $\begin{array}{l}\text { Biotita ortognaisse } \\
\text { monzogranítico }\end{array}$ & 31 & 22 & 40 & - & - & - & 5 & - & - & - & - & - & - & 2 & - & - \\
\hline & GESE 266-A & $\begin{array}{c}\text { Biotita ortognaisse } \\
\text { tonalítico } \\
\text { Hornblenda ortognaisse }\end{array}$ & 67 & 28 & - & - & - & - & 5 & - & - & - & - & - & - & - & - & $\operatorname{tr}$ \\
\hline & GESE 266-B & $\begin{array}{l}\text { granodiorítico com biotita e } \\
\text { epídoto }\end{array}$ & 45 & 22 & 12 & - & - & - & 3 & 15 & - & - & - & - & 2 & - & 1 & - \\
\hline & GESE 320 & $\begin{array}{l}\text { Hornblenda-biotita } \\
\text { ortognaisse granodiorítico }\end{array}$ & 57 & 18 & 12 & - & - & - & 7 & 5 & - & - & - & - & - & - & 1 & - \\
\hline & GESE 321 & $\begin{array}{l}\text { Biotita ortognaisse } \\
\text { granodiorítico }\end{array}$ & 57 & 22 & 15 & - & - & 1 & 5 & - & - & - & - & - & - & - & - & - \\
\hline & GESE & $\begin{array}{l}\text { Biotita ortognaisse } \\
\text { tonalítico }\end{array}$ & 69 & 23 & 3 & - & - & - & 5 & - & - & - & - & - & - & - & - & - \\
\hline & GESE & $\begin{array}{l}\text { Biotita ortognaisse } \\
\text { tonalítico }\end{array}$ & 67 & 25 & - & - & - & 1 & 7 & - & - & - & - & - & - & - & - & - \\
\hline & GESE 336 & $\begin{array}{l}\text { Hornblenda-biotita } \\
\text { ortognaisse tonalítico }\end{array}$ & 69 & 18 & - & - & - & - & 7 & 04 & - & - & - & - & 2 & - & - & - \\
\hline \multirow{3}{*}{$\begin{array}{l}\text { Níveis } \\
\text { anfibolíticos }\end{array}$} & GESE 261-C & $\begin{array}{l}\text { Granada anfibolito } \\
\text { (metagabro) }\end{array}$ & 28 & 05 & - & - & - & 2 & - & - & - & 55 & $\operatorname{tr}$ & - & - & 10 & - & $\operatorname{tr}$ \\
\hline & GESE 264-B & Anfibolito & 40 & 18 & - & - & - & 2 & - & 35 & - & - & $\operatorname{tr}$ & - & - & 05 & $\operatorname{tr}$ & - \\
\hline & GESE 334 & $\begin{array}{l}\text { Granada anfibolito } \\
\text { (metagabro ou } \\
\text { calcicossilicática) }\end{array}$ & 30 & - & - & - & - & 2 & - & 37 & 5 & - & $\operatorname{tr}$ & - & - & 25 & 1 & - \\
\hline
\end{tabular}

tr: mineral traço. 
Tabela 2. Análises químicas de rocha total dos ortognaisses do Domo de Itabaiana (Tipos I e II) e das rochas anfibolíticas (Níveis Am).

\begin{tabular}{|c|c|c|c|c|c|c|c|c|c|c|c|c|c|c|c|c|c|c|c|c|}
\hline \multirow[b]{2}{*}{ mostra } & \multicolumn{11}{|c|}{ Grupo Tipo I } & \multicolumn{7}{|c|}{ Grupo Tipo II } & \multicolumn{2}{|c|}{ Niveis Am } \\
\hline & $\begin{array}{c}\text { GESE } \\
313\end{array}$ & $\begin{array}{c}\text { GESE } \\
336\end{array}$ & $\begin{array}{l}\text { GESE } \\
\text { 266B }\end{array}$ & $\begin{array}{l}\text { GESE } \\
261 \mathrm{~A}\end{array}$ & $\begin{array}{l}\text { GESE } \\
264 A\end{array}$ & $\begin{array}{c}\text { GESE } \\
320\end{array}$ & $\begin{array}{c}\text { GESE } \\
323\end{array}$ & $\begin{array}{c}\text { GESE } \\
272\end{array}$ & $\begin{array}{l}\text { GESE } \\
269 \mathrm{~B}\end{array}$ & $\begin{array}{l}\text { GESE } \\
266 \mathrm{~A}\end{array}$ & $\begin{array}{c}\text { GESE } \\
324\end{array}$ & $\begin{array}{c}\text { GESE } \\
321\end{array}$ & $\begin{array}{l}\text { GESE } \\
261 \mathrm{~B}\end{array}$ & $\begin{array}{l}\text { GESE } \\
254 A\end{array}$ & $\begin{array}{c}\text { GESE } \\
251\end{array}$ & $\begin{array}{c}\text { GESE } \\
253\end{array}$ & $\begin{array}{c}\text { GESE } \\
323\end{array}$ & $\begin{array}{c}\text { GESE } \\
252\end{array}$ & $\begin{array}{l}\text { GESE } \\
\text { 261C }\end{array}$ & GESE \\
\hline & 63,25 & 64,500 & 65,540 & 67,610 & 6 & 6 & 69,4 & 0,590 & 70,670 & ,300 & 72,140 & 70,590 & 070,920 & 071,120 & 0 & & & 610 & 50,42 & . \\
\hline & 30 & 450 & 0,330 & 0,310 & 0,150 & 0,230 & 0,270 & 0,250 & 0,220 & 0,200 & 0,190 & 0,180 & 0,220 & 0,18 & 0,1 & 190 & 0,17 &, 100 & 0,89 & 0,6 \\
\hline $\mathrm{O}_{3}$ & 16,760 & 15,020 & 15,770 & 16,080 & 15,780 & 16,340 & 16,190 & 15,890 & 15,380 & 015,780 & 15,610 & 15,850 & 015,690 & 015,50 & 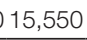 & 14,9 & , & 4,660 & 14,50 & , \\
\hline $0+$ & 05,280 & 5,380 & 4,120 & 2,930 & 2,900 & 2,090 & 2,670 & 2,170 & 2,820 & 1,770 & 1,600 & 2,580 & 1,920 & 1,760 & 1,570 & 1,780 & 1,810 & 1,250 & 13,10 & $\overline{9,6}$ \\
\hline & 0,060 & 0,080 & 0,050 & 0,030 & 0,050 & 30 & 30 & 0,020 & 0,050 & 0,010 & 0,020 & 0,040 & 0,020 & 0,020 & 20 & 20 & 0,030 & 0,020 & 24 & 40 \\
\hline & 80 & & 2,540 & 2,020 & 2,010 & 60 & 20 & 0,660 & 0,830 & 0,570 & 0,430 & 0,820 & 0,660 & 0,430 & & 70 & 10 & 0,320 & 73 & \\
\hline & 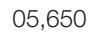 & & 4,040 & 970 & 3,690 & & 3 & 020 & 2,890 & 2,390 & 2,910 & 260 & 1 & 1,780 & & 70 & & 570 & 1 & \\
\hline & 0 & & 4,780 & 5 & 5,120 & 0 & 5 & 5,200 & 4 & 5,710 & 5,330 & 60 & 5,000 & 4,970 & & & & 690 & 6 & \\
\hline & b & & 1,740 & & 1,000 & & 30 & 340 & bo & 1,200 & 0,970 & 3,370 & 2,950 & 3,330 & 50 & 10 & 70 & 100 & 4 & 976 \\
\hline & 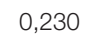 & 0 & 10 & 0 & 0,050 & & 0 & 0,070 & 0,070 & 0,090 & 0,030 & 0,080 & 0,070 & 0,060 & & 50 & & 0,030 & 6 & ,09c \\
\hline & $<0,002$ & $<0,002$ & 0,017 & 0,004 & 0,0130 & $<0,002$ & 20,003 & $<0,002$ & $<0,002$ & $<0,002$ & $<<0,002$ & 0,003 & $<0,002$ & $2<0,00$ & 0,002 & & & 0,002 & 07 &, 046 \\
\hline & 1,200 & 3,200 & 0,700 & 1,600 & 1,000 & 0,400 & 0,400 & 0,500 & 0,500 & 0,600 & 0,700 & 1,200 & 0,900 & 0,600 & & 00 & 0 & 0,500 & 1,20 & 70 \\
\hline & 99,730 & 99 , & 99,720 & 99,730 & 99,790 & 99,650 & 99,830 & 99,730 & 99,810 & D99,610 & 99,900 & 99,700 & 99,820 & 99,740 & 760 & 760 & 10 &, 840 & 99,73 & , \\
\hline & 900 & 0 , & 0,920 & 1,130 & 0,970 & 1,000 & 1,030 & 1,020 & 1 & 1,0 & 1,030 & 0,970 & 1 & 1,030 & & & & 050 & 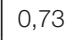 & \\
\hline & D & c & 360 & ( & 0,200 & 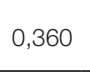 & c & 60 & c & 0 & 80 & 0,650 & 0 & 0,670 & 0 & 0 & D & ( & 0,56 & \\
\hline & & & & & & & & & & & & & & & & & & & & \\
\hline & & & & & & & & & & & & & & & & & & & & \\
\hline & & & 6 & 4 & 2.0 & & 34 & 26 & 2 & & 1 & 5,0 & 0 & 13 & & & & & & 5,0 \\
\hline & & & & & & & & & & & & & & & & & & & & \\
\hline & & & 5,6 & & 4 & & & & & & & & & & & & & & &, 2 \\
\hline & & & & & & & & & & & & & & 1 & & & & & & 6 \\
\hline & & & 3 & & 7,0 & & & & & & & & & 28 & & & & & & \\
\hline & & & & & & & & & & & & & & 8 & & & & & & \\
\hline & & & 827,0 & & 56 & & & & & & & 1.271 & & $01.218,0$ & 7,0 & & & 4,0 & & \\
\hline & & 4 & 656,2 & 609,4 & 627,6 & & 510,8 & 772,7 & 311,7 & 1.0 & 527,8 & 564,9 & & 481,7 & & & 2,1 & 8,5 & 3,6 & 3 \\
\hline & & & & & & & & & & & & & & & & & & & & \\
\hline & & & & & 1,6 & & 16 & & 16 & & 7 & 5,6 & 5 & 18,7 & & & & 0 & , &, 1 \\
\hline & & & & & & & & & & & & & & & & & & & & \\
\hline & & & $0,2,0$ & 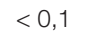 & $<0,1$ & 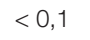 & & $<0,1$ & & 1 & $<$ & & 1 & 0,2 & & & & & & 1 \\
\hline & & & & & & & & & & & & & & & & & & & & \\
\hline & & & & & & & & & & & & & & & & & & & & 4 \\
\hline & & & & & & & & & & & & & & 11 & & & & & & \\
\hline & & & 6,5 & & & & & & & & & 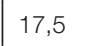 & & & & & & & 0,6 & 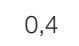 \\
\hline & & & & & $<0$ & & & & & & & & & & & & & & $<0,1$ & $<0,1$ \\
\hline & & & 0,6 & & & & & & & & & & & 1,4 & & & & & 1,0 & 1 \\
\hline & & & & & & & & & & & & & & & & & & & & \\
\hline & 0 & 10 & 35,80 & 42,70 & 14 & 0 & 2 & 50 & 10 & 0 & 16 & 0 & 30 & 34,50 & & 70 & 00 & 60 & ,20 & 10 \\
\hline & & & & & & & & & & & & & & & & & & & & \\
\hline & 70 & 0 & 13,20 & 16,00 & 5,5 & 0 & 10,00 & & 12 & & & 0 & 22 & 10,20 & & & & & & 30 \\
\hline & & & & & & & & & & & & & & & & & & & & \\
\hline & & & & & & & & & & & & & & & & & & & & 96 \\
\hline & & & & & & & & & & & & & & & & & & & & \\
\hline & & & & & & & & & & & & & & & & & & & & 0 \\
\hline & & & & & & & & & & & & & & & & & & & 0 & 54 \\
\hline & & & 0,2 & & & & & & & & & & & & & & & & 33 & 67 \\
\hline & & & & & & & & & & & & & & 0, & & & & & 40 & 87 \\
\hline & & & 0,0 & & & & & & & & & & 4 & 3 & & 2 & 8 & 44 & 40 & 28 \\
\hline & & & & & & & & & & & & & & 0, & & & & & & 1,65 \\
\hline & ,18 & 0,17 & 0,08 & 0,09 & 0,05 & 03 & 0,0 & 0,02 & 0,09 & 0,01 & 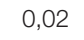 & ,08 & 0,04 & 0,03 & 06 & ,02 & ,08 & 0,04 & ,38 & 23 \\
\hline alv/ &, 32 & 14,21 & 02 & 71 & 92 & 37 & 61 & 55 & 25,12 & 119,48 & 3,35 & 6 & 03 & 5,9 & 127,47 & 70,10 & 9,25 & 3,50 & 3,98 & 17,6 \\
\hline
\end{tabular}

A/CNK: Al2O3/(CaO + Na2O + K2O); LOI: perda ao fogo. Elementos maiores em \% em peso e traço em ppm. 
uma afinidade trondhjemítica, mesmo tendo algumas diferenças entre si, apresentando similaridades com suítes TTG arqueanas, embora as rochas do Tipo II apresentem enriquecimento em $\mathrm{K}_{2} \mathrm{O}$ e $\mathrm{Rb}$, seguindo o trend cálcio-alcalino, quando comparado com o Tipo I.

\section{Elementos-traço e terras raras}

Para os ortognaisses do Domo de Itabaiana, foram analisados espectros de elementos-traço e terras raras dos dois grupos
(Tipos I e II). Os diagramas multielementares (Figuras 10A e 10C) foram normalizados segundo os parâmetros do manto primitivo de Wood et al. (1979). Segundo Martin (1993, 1994) e Martin et al. (2005), TTGs arqueanos apresentam expressiva anomalia negativa de $\mathrm{Nb}$-Ta-Ti e $\mathrm{P}$, mostrando que houve fracionamento de apatita (fase acessória) durante a diferenciação (Martin, 1993).

Analisando inicialmente o gráfico do grupo Tipo I, percebem-se significativas anomalias negativas de $\mathrm{Th}-\mathrm{U}, \mathrm{Ta}-\mathrm{Nb}$ e Ti, baixos teores de $\mathrm{Y}$ e anomalias positivas de $\mathrm{Ba}, \mathrm{K}$ e
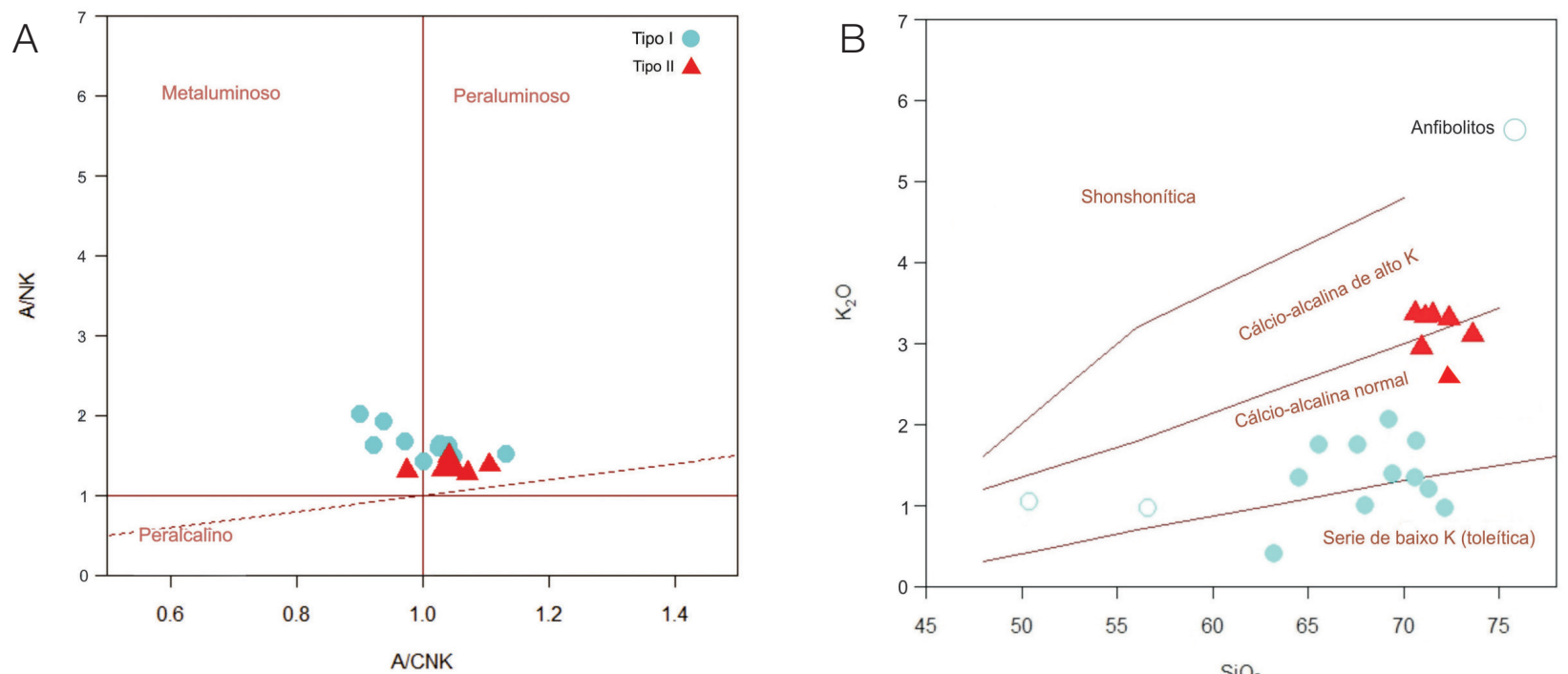

Tipo I: círculos azuis; Tipo II: triângulos vermelhos; círculos vazados: rochas anfibolíticas; $\mathrm{A}: \mathrm{Al}_{2} \mathrm{O}_{3} ; \mathrm{CNK}: \mathrm{CaO}+\mathrm{Na}_{2} \mathrm{O}+\mathrm{K}_{2} \mathrm{O} ; \mathrm{NK}_{2}: \mathrm{Na}_{2} \mathrm{O}+\mathrm{K}_{2} \mathrm{O}$.

Figura 7. (A) Diagrama molar A/CNK versus ANK ou diagrama de Shand (1943), mostrando a classificação química das rochas ortognáissicas do Domo de Itabaiana quanto a alumina-saturação. (B) Diagrama $\mathrm{SiO}_{2}$ versus $\mathrm{K}_{2} \mathrm{O}$ (Peccerillo e Taylor, 1976).
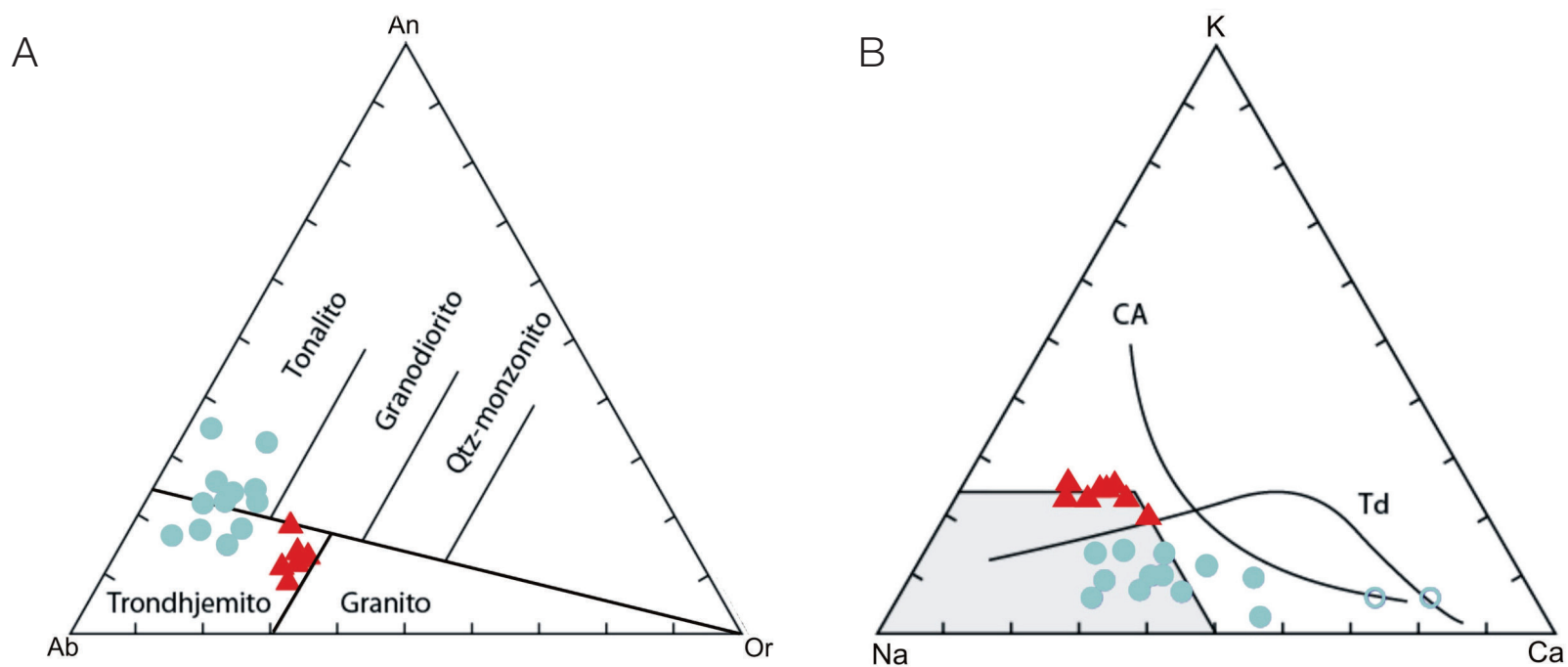

CA: trend cálcio alcalino clássico; Td: trend trondhjemítico; campo cinza: campo dos TTGs arqueanos (Martin, 1994); círculos azuis: Tipo I; triângulos vermelhos: Tipo Il; círculos vazados: rochas anfibolíticas.

Figura 8. (A) Diagrama Ab-An-Or de O’Connor (1965) para os ortognaisses do Domo de Itabaiana; (B) diagrama Na-K-Ca para os ortognaisses do Domo de Itabaiana. 
Sr. Esse conjunto de características aponta para uma gênese em ambiente de subducção, aparentemente sem influência crustal, em função das fortes anomalias negativas de Th e U.

Com relação ao grupo Tipo II, percebe-se que as anomalias de Th e U são bem menos acentuadas e que as anomalias positivas de $\mathrm{Sr}$ são menos expressivas, em comparação com as amostras do Tipo I. Por outro lado, as anomalias negativas de Ti são mais expressivas. Pode-se afirmar também, ao analisar o espectro, que os valores de Y são relativamente menores no Tipo II. Além disso, em relação ao
$\mathrm{K}$, percebe-se que as amostras do grupo Tipo II são mais enriquecidas. Essas características revelam que o Tipo II é mais diferenciado que o Tipo I e que, em sua gênese, parece ter ocorrido alguma participação crustal.

Rochas do tipo TTG são caracterizadas por altas razões $\mathrm{La} / \mathrm{Yb}$, refletindo em um forte fracionamento de elementos terras raras leves em relação aos pesados. Além disso, os padrões de elementos terras raras dessas rochas tendem a tomar forma côncava em relação aos terras raras pesados (Martin et al., 2005).
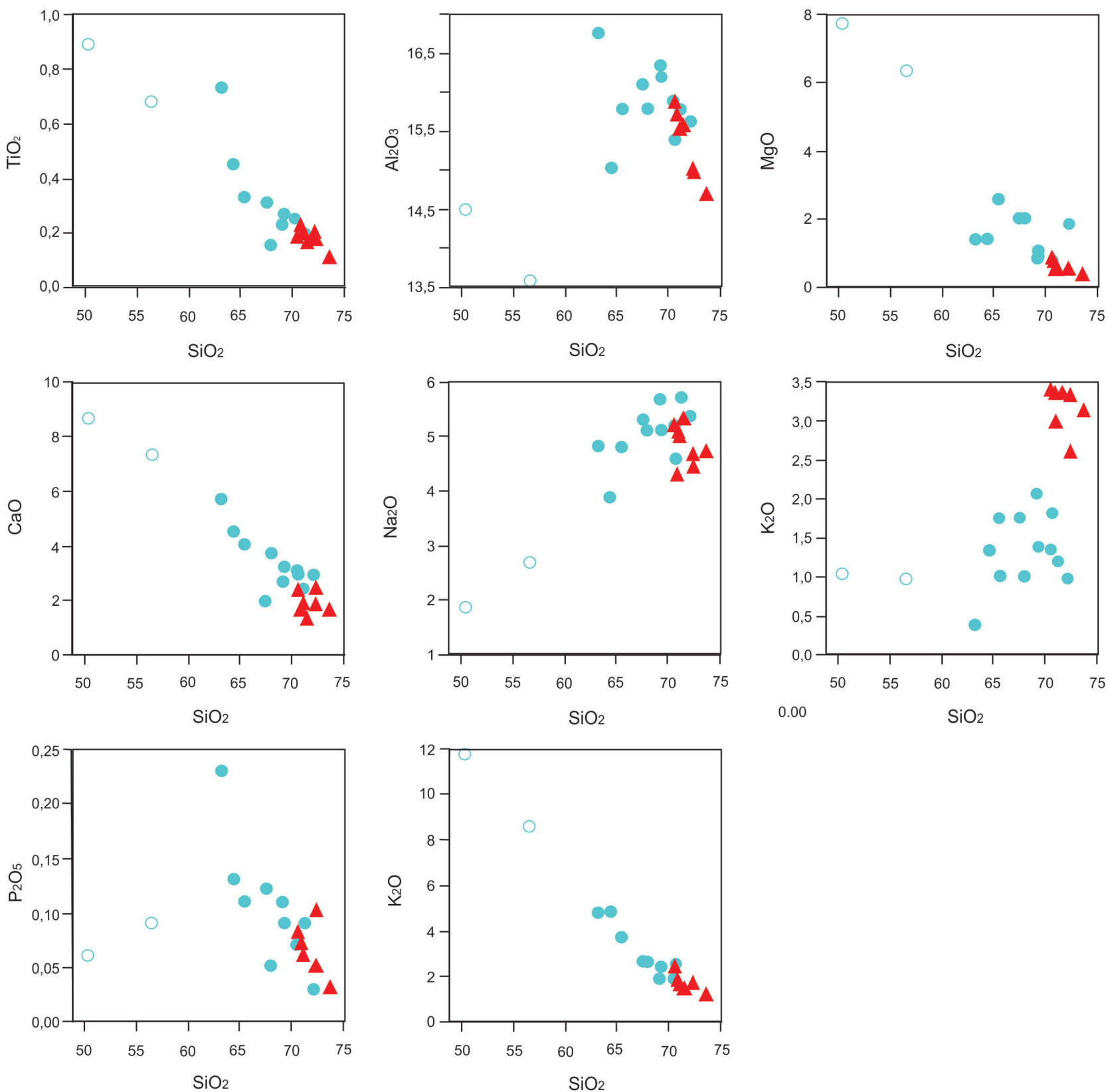

Círculos azuis: Tipo I; triângulos vermelhos: Tipo Il; círculos vazados: rochas anfibolíticas.

Figura 9. Diagramas de $\mathrm{SiO}_{2}$ (\% em peso) versus elementos maiores (\% em peso) para os ortognaisses do Domo de Itabaiana. 
Os padrões de elementos terras raras (Figuras 10B e 10D) dos Tipos I e II, normalizados em relação aos valores do condrito de Boynton (1984), revelam que as rochas dos Tipos I e II exibem um forte fracionamento dos terras raras pesados, em relação aos leves (Tipo I: $6,32<\mathrm{La} / \mathrm{Yb}_{\mathrm{n}}$ $<119,48$; Tipo II: $\left.1,76<\mathrm{La} / \mathrm{Yb}_{\mathrm{n}}<124,74\right)$, com discretas a ausentes anomalias positivas de Eu e concavidade no padrão dos elementos terras raras pesados. Esses padrões são semelhantes aos descritos por Moyen e Martin (2012) para típicos TTGs arqueanos. Já no Tipo II, os espectros parecem seguir o trend cálcio-alcalino normal, sem ou com fracas anomalias positivas de Eu em algumas amostras.

Segundo Martin (1994) e Martin et al. (2005), rochas da suíte TTG são caracterizadas por teores de $\mathrm{Sr}$ elevados (> $454 \mathrm{ppm}$ ), tendo, consequentemente, baixas razões $\mathrm{Rb} /$ $\mathrm{Sr}$ (entre 0,05 e 1,0$)$. Utilizando os diagramas de descriminação de ambiente tectônico de Pearce et al. (1984), para rochas de composição granítica, com base nos elementos-traço, as amostras de ortognaisses plotam no campo de ambiente do tipo arco magmático, sugerindo que essas rochas podem ter sido formadas em ambiente de subducção (Figura 11).
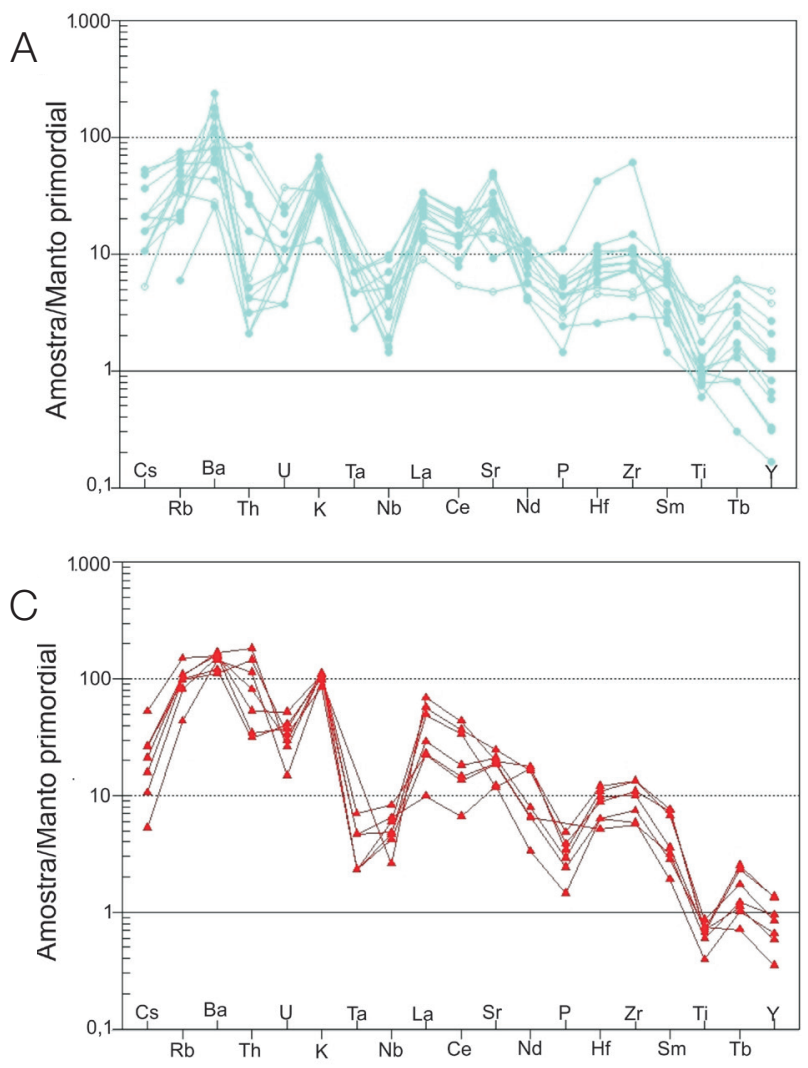

\section{GEOCRONOLOGIA}

Foram separados 18 grãos de zircão e suas razões isotópicas $\mathrm{U}-\mathrm{Pb}$ foram dosadas por LA-ICP-MS. Assim, foi determinada uma idade de cristalização para os ortognaisses do Domo de Itabaiana. Os dados analíticos são mostrados na Tabela 3.

Em relação à morfologia, os cristais de zircão (Figura 12) apresentam-se tipicamente euédricos, em tons que variam de marrom claro a transparente, com bordas arredondadas. Sob CL, apresentam zoneamento oscilatório, com alguns grãos apresentando núcleos herdados, bem escuros e arredondados. Outros grãos apresentam borda ígnea, definida pela alternância de cores na imagem de CL. Alguns apresentam borda altamente luminescente e núcleos de alto $\mathrm{U}$ (núcleos escuros), os quais encontram-se corroídos e sobrecrescidos por borda irregular mais pobre em $\mathrm{U}$.

No diagrama concórdia (Figura 13), as análises no zoneamento (21 análises) plotam ao longo de uma discórdia e apresentam uma idade, por intercepto superior, de $2.729 \pm 12$ (MSWD $=1,4)$, sendo esta interpretada como a idade de cristalização da rocha. Os núcleos herdados (em vermelho) definiram uma idade concórdia em aproximadamente $2.847 \pm 9(\mathrm{MSWD}=0,13)$.
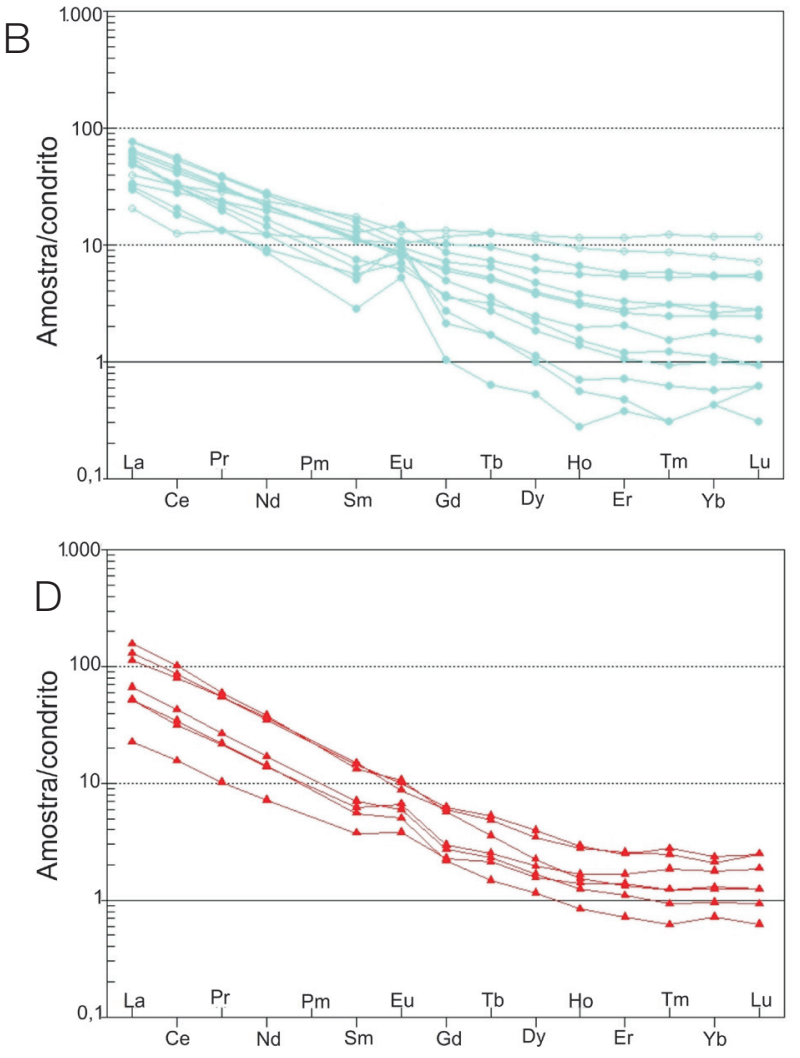

Círculos azuis: Tipo I; triângulos vermelhos: Tipo Il; círculos vazados: rochas anfibolíticas.

Figura 10. (A) e (C) Diagramas multielementares para as rochas ortognáissicas dos grupos Tipo I e II, normalizados segundo os dados de manto primitivo de Wood et al. (1979). (B) e (D) Diagramas mostrando o padrão dos elementos terras raras para as rochas ortognáissicas dos Tipos I e II, normalizados segundo os dados do condrito de Boynton (1984). 

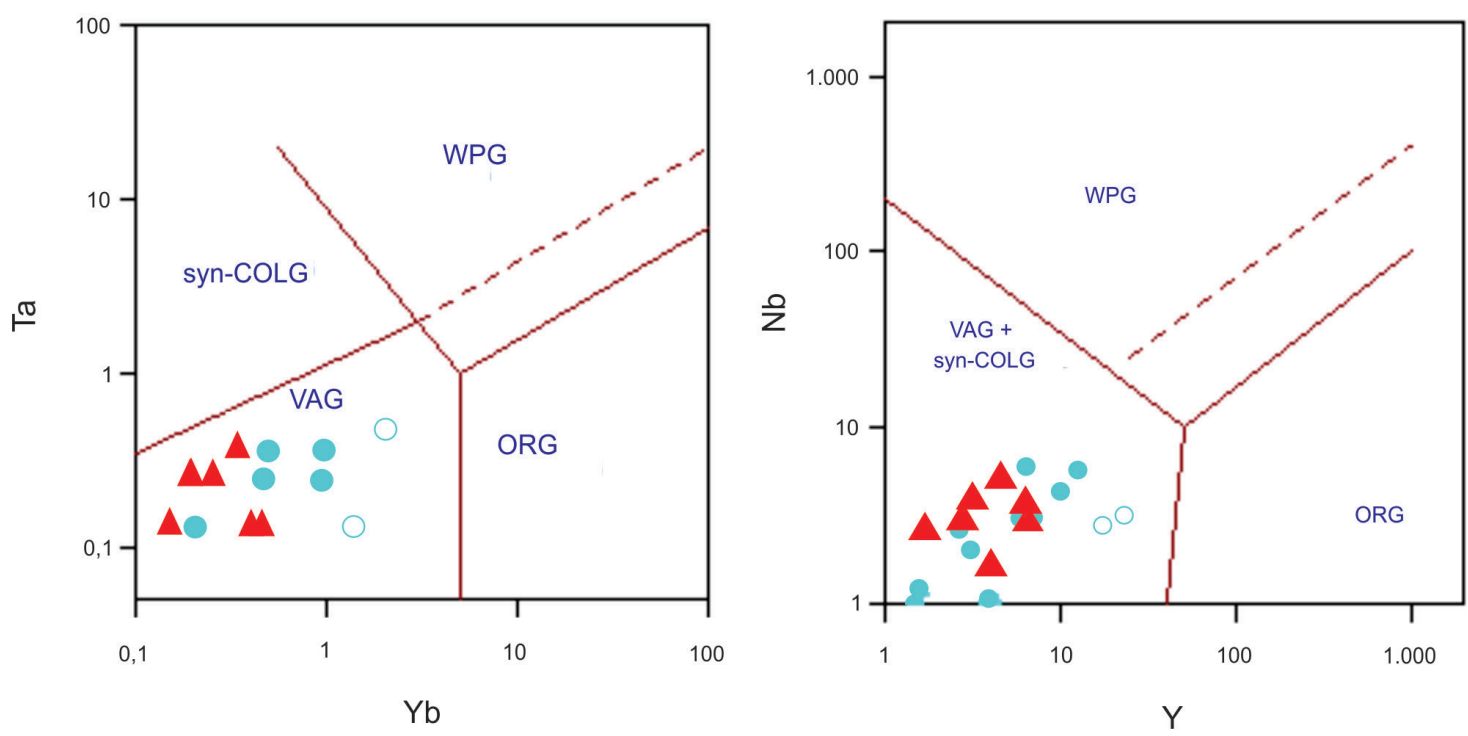

Círculos azuis: Tipo I; triângulos vermelhos: Tipo II; círculos vazados: rochas anfibolíticas; VAG: granitoides de arco vulcânico; Syn-COLG: granitoides sincolisionais; WPG: granitoides intraplaca; ORG: granitoides de fundo oceânico.

Figura 11. Diagramas descriminantes de ambientes tectônicos para as amostras de ortognaisse, segundo Pearce et al. (1984).

Tabela 3. Dados analíticos U-Pb por LA-ICP-MS da amostra GESE 266-A. Coordenadas do ponto: 666566/8813932.

\begin{tabular}{|c|c|c|c|c|c|c|c|c|c|c|c|c|c|c|c|c|}
\hline \multicolumn{17}{|c|}{ Análises U_Pb LA-ICP-MS } \\
\hline \multirow[b]{2}{*}{ Análises_\# } & \multirow[b]{2}{*}{ Th/U } & \multicolumn{6}{|c|}{ Razões isotópicas } & \multirow[b]{2}{*}{ Rho } & \multicolumn{6}{|c|}{ Idades (Ma) } & \multirow[b]{2}{*}{$\begin{array}{c}\text { Disc. } \\
\%\end{array}$} & \multirow[b]{2}{*}{ Conc. } \\
\hline & & $\begin{array}{l}\mathrm{Pb}^{207 /} / \\
\mathrm{Pb}^{206} \\
\end{array}$ & $1 \sigma$ & $\begin{array}{c}\mathrm{Pb}^{206 /} \\
\mathrm{U}^{238}\end{array}$ & $1 \sigma$ & $\begin{array}{c}\mathrm{Pb}^{207} \mathrm{I} \\
\mathrm{U}^{235}\end{array}$ & $1 \sigma$ & & $\begin{array}{l}\mathrm{Pb}^{207 /} / \\
\mathrm{Pb}^{206}\end{array}$ & $1 \sigma$ & $\begin{array}{c}\mathrm{Pb}^{206} / \\
\mathrm{U}^{238}\end{array}$ & $1 \sigma$ & $\begin{array}{c}\mathrm{Pb}^{207} / \mathrm{I} \\
\mathrm{U}^{235}\end{array}$ & $1 \sigma$ & & \\
\hline \multicolumn{17}{|l|}{ GESE 266-A } \\
\hline \multicolumn{17}{|l|}{ Núcleos } \\
\hline 4.sSMF & 0,206 & 0,20147 & 0,0035 & 0,55628 & 0,0058 & 15,481 & 2288 & 0,705 & $2.838,1$ & 27,9 & $2.851,2$ & 24,00 & $.845,3$ & 14,10 & 0 & 00,2 \\
\hline 9 & 0,290 & 0,20224 & 0,0029 & 0,55626 & 0,0046 & 15,532 & 1 & 0,702 & $2.844,4$ & 23,4 & $2.851,1$ & 9,00 & 848,5 & 18 & 0 & 00,1 \\
\hline \multicolumn{17}{|l|}{ Grãos } \\
\hline 4.SSMPA & 0,019 & 0,18967 & 0,0021 & 0,5315 & 0,0032 & 13,908 & 0,1024 & 0,825 & $2.739,3$ & 18,4 & $2.747,8$ & 13,60 & $2.743,5$ & 6,97 & 0 & 100,2 \\
\hline 4.sSMPABC051 & 0,403 & 0,18655 & 0,0030 & 0,5226 & 0,0047 & 13,459 & 0,1852 & 0,658 & $2.712,0$ & 26,5 & $2.710,2$ & 20,00 & $2.712,4$ & 13,01 & 0 & 99,9 \\
\hline 4.sSMPABC025 & 0,263 & 0,18745 & 0,0024 & 0,5158 & 0,0039 & 13,342 & 0,1305 & 0,767 & $2.719,9$ & 21,3 & $2.681,4$ & 16,50 & $2.704,2$ & 9,24 & 1 & 99,1 \\
\hline 4.sSMPABC022 & 0,096 & 0,18336 & 0,0026 & 0,45658 & 0,0036 & 11,551 & 0,1287 & 0,710 & $2.683,5$ & 23,3 & $2.424,5$ & 16,00 & $2.568,7$ & 10,41 & 6 & 94,1 \\
\hline 4.sSMPABC078 & 0,528 & 0,18389 & 0,0029 & 0,44599 & 0,0038 & 11,324 & 0,1548 & 0,630 & $2.688,3$ & 26 & $2.377,4$ & 17,10 & $2.550,2$ & 12,75 & 7 & 92,7 \\
\hline 4.sSMPABC023 & 0,272 & 0,18441 & 0,0037 & 0,44559 & 0,0055 & 11,327 & 0,2008 & 0,698 & $2.692,9$ & 32,4 & $2.375,6$ & 24,60 & $2.550,4$ & 16,54 & 7 & 92,6 \\
\hline 4.sSMPABC062 & 0,145 & 0,18164 & 0,0035 & 0,42936 & 0,0040 & 10,765 & 0,1828 & 0,550 & $2.667,9$ & 31,3 & $2.302,8$ & 18,10 & $2.503,1$ & 15,78 & 8 & 91,3 \\
\hline 4.sSMPABC065 & 0,288 & 0,17866 & 0,0030 & 0,42055 & 0,0039 & 10,375 & 0,1466 & 0,660 & $2.640,5$ & 27,1 & $2.263,0$ & 17,80 & $2.468,8$ & 13,08 & 8 & 90,9 \\
\hline $4 . s$ & 0,147 & 838 & 20 & 9039 & 0 , & 3 & 4 & 0,811 & 7,9 & 3 & 6 & 30 & $2.398,4$ & 5 & 11 & 87,1 \\
\hline 4.sSMP & 0,046 & 0,17713 & 0,0022 & 37402 & 0 , & 9,142 & 4 & 0,698 & , 2 & 20,9 & 3 & 0 & 2,3 & 8 & 13 & ,2 \\
\hline 4.sSMPABC074 & 0,149 & 0,16968 & 0,0030 & 236 & 0, & 8 & 0 & 0,557 & 54,5 & 29,3 &, 5 & 5,40 & 9,5 & 14,36 & 12 & 86,8 \\
\hline 4.sSMPABC038 & 0,144 & 0,17157 & 0,0020 & 0,36103 & 0,0 & 8,552 & 0,0660 & 0,768 & 73,0 & 1. & 7,1 & 10,10 & 1,5 & 7,01 & 13 & 84,7 \\
\hline 4.sSMPABC024 & 0,054 & 0,17267 & 0,0021 & 0,3516 & 0,0 & 8,381 & 11 & 0,751 & $2.583,7$ & 20 & $1.942,2$ & , & $.273,1$ & 7,70 & 15 & 83,0 \\
\hline 4.sSMPABC052 & 0,134 & 0,16881 & 026 & 0,31018 & 0,0023 & 7,229 & 0,0 & 0,593 & $2.545,9$ & 25,4 & $1.741,6$ & 1,40 & $2.140,1$ & 11,26 & 19 & 77,1 \\
\hline 4.sSMPABC067 & 0,037 & 0,16315 & 0,0039 & 0,2903 & 0 & 6,541 & 0,1 & 0,517 & $2.488,6$ & 39,6 & $1.643,0$ & 16,60 & $2.051,4$ & 19,49 & 0 & 75,1 \\
\hline 4.sSMPABC077 & 0,079 & 0,15846 & 0,0035 & 0,28488 & 0,0031 & 6,228 & 0,1 & 0,536 & $2.439,3$ & 36,4 & $1.615,9$ & 15,50 & $2.008,4$ & 17,63 & 20 & 75,7 \\
\hline 4.sSMPABC030 & 0,066 & 0,16193 & 0,0022 & 0,27498 & 0,0019 & 年 & 0,0621 & 0,673 & $2.475,9$ & 22,6 & $1.566,0$ & 9,44 & $1.996,5$ & 8,82 & 22 & 然 \\
\hline 4.sSMPA & 32 & 0,15835 & 0,0019 & 0,27167 & 0,0016 & ,937 & 5 & 57 & $2.438,1$ & 19,6 & 3 & 6 & ,7 & 0 & 1 & 73,1 \\
\hline 4.sSMPABC066 & 0,069 & 0,15846 & 0,0028 & 0,2697 & 0,0024 & 5,902 & 0,0900 & 0,581 & $2.439,3$ & 29,2 & $1.539,3$ & 12,10 & $.961,5$ & 13,23 & 22 & 72,6 \\
\hline 4.sSMPABC021 & 0,030 & 0,15478 & 0,0019 & 0,2579 & 0,0015 & 5,508 & 0,0453 & 0,726 & $2.399,4$ & 20,3 & $1.479,1$ & 7,87 & $1.901,9$ & 7,07 & 22 & 71,4 \\
\hline 4.sSMPABC068 & 0,102 & 0,11504 & 0,0017 & 15912 & 0,0011 & 2,527 & ,0297 & 0,610 & $1.880,5$ & 25,7 & 951,9 & 6,36 & $1.279,9$ & 8,54 & 26 & 65,5 \\
\hline
\end{tabular}



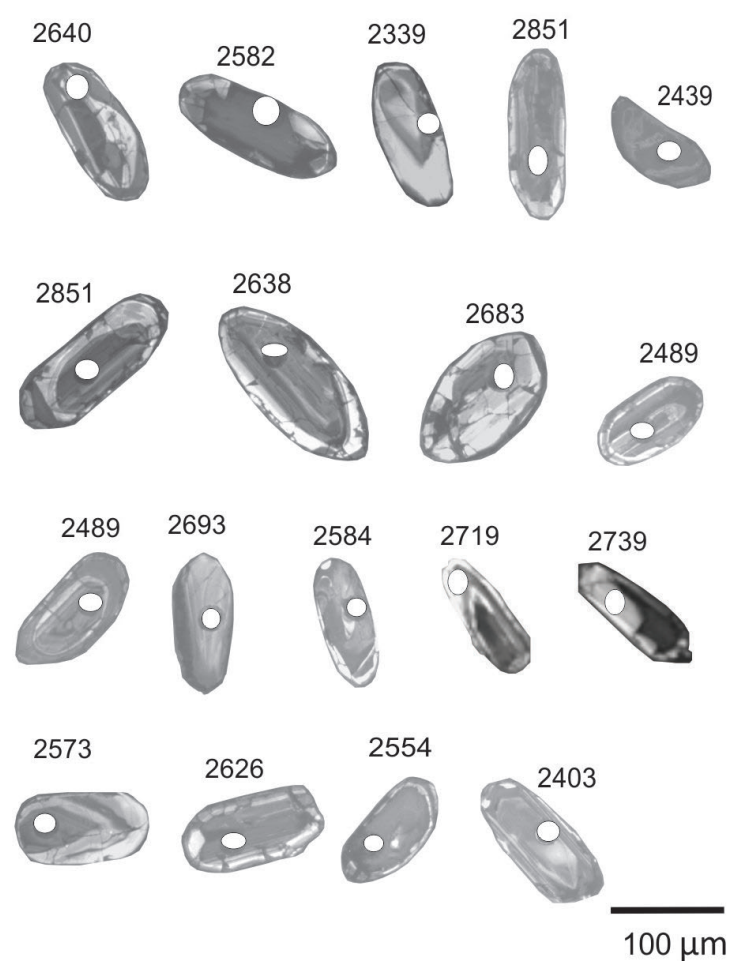

Figura 12. Montagem de imagens dos grãos de zircão analisados do ortognaisse, em catodoluminescência, sob luz transmitida - Amostra GESE 266-A. Os círculos apresentados nas imagens dos zircões representam pontos analisados. As idades apresentadas são ${ }^{207} \mathrm{~Pb} /{ }^{206} \mathrm{~Pb}$.

\section{CONCLUSÕES}

Os dados apresentados sugerem que as rochas estudadas são semelhantes às rochas das suítes TTGs arqueanas e, possivelmente, cronocorrelatas com as rochas arqueanas do Domo de Simão Dias. Os dados geoquímicos sugerem a existência de dois grupos distintos, fortemente sódicos $\left(\mathrm{K}_{2} \mathrm{O} / \mathrm{Na}_{2} \mathrm{O}<0,5\right)$, para os ortognaisses, denominados de Tipo I e Tipo II. O Tipo I, de mais baixo $\mathrm{K}\left(\mathrm{K}_{2} \mathrm{O}<2,5 \%\right)$, posiciona-se na transição entre as séries de baixo $\mathrm{K}$ e as séries cálcio-alcalinas normais e no campo dos TTGs. O Tipo II, com teores de $\mathrm{K}_{2} \mathrm{O}$ superiores a iguais a 2,5\%, posiciona-se na interface entre as séries cálcio-alcalinas normais e cálcio-alcalinas de alto $\mathrm{K}$, mostrando certo enriquecimento em $\mathrm{K}$.

As anomalias negativas de $\mathrm{Ta}-\mathrm{Nb}$ presentes nos diagramas multielementares, tanto do Tipo I como do Tipo II, apontam para uma gênese em ambiente de subducção. Os padrões de terras raras do Tipo I, com forte fracionamento, empobrecimento de terras raras pesados e anomalias levemente positivas de Eu são típicos da evolução de um líquido trondhjemítico. Já o padrão do Tipo II, também com espectros fracionados, sem expressivas anomalias positivas de $\mathrm{Eu}$, são semelhantes aos padrões de rochas da série cálcio alcalina normal. As análises geocronológicas apontam para uma idade de 2729 $\pm 12 \mathrm{Ma}$, interpretada como sendo a idade de cristalização dos ortognaisses. O conjunto de dados apresentados permite concluir que os ortognaisses do Domo de Itabaiana apresentam todas as características das típicas associações TTGs arqueanas (Martin, 1994; Martin et al., 2005; Moyen e Martin, 2012).

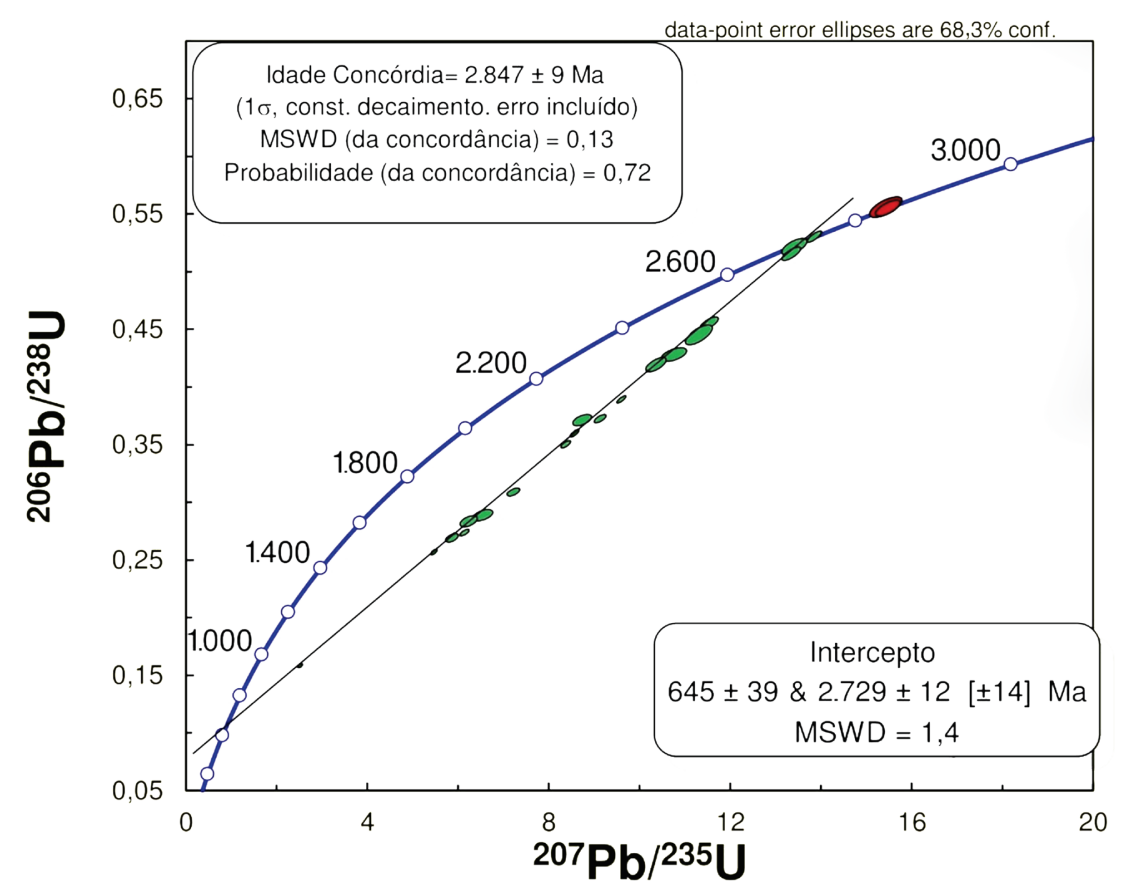

Figura 13. Diagrama Concórdia U-Pb mostrando idade de cristalização dos ortognaisses em aproximadamente $2729 \pm 12$ Ma. Amostra GESE 266-A. 


\section{AGRADECIMENTOS}

Os autores agradecem ao Projeto GEOTERM-SEAL, em nome do Prof. Roberto Max Argolo, pelo auxílio de campo, pela confecção de lâminas petrográficas e pelas análises geoquímicas. A Coordenação de Aperfeiçoamento de Pessoal do Nível Superior (CAPES), pela concessão da bolsa de estudos do primeiro autor, ao Projeto CNPq (Processo n ${ }^{\circ} 476901 / 2013-8$ ) e aos revisores.

\section{REFERÊNCIAS}

Barker, F. (1979). Trondhjemite: definition, environment and hypotheses of origin. In: F. Barker. Trondhjemites, Dacites, and Related Rocks (1-12). Amsterdã: Trondhjemites, Dacites, And Related Rocks.

Barker, F., Arth, J. G. (1976). Generation of trondhjemitetonalitic liquids and Archaean bimodal trondhjemite-basalt suites. Geology, 4, 596-600.

Boynton, W. V. (1984). Cosmochemistry of the rare earth elements: meteoritic studies. In: P. Henderson (Ed.), Rare Earth Elements Geochemistry (63-114). Amsterdã: Elsevier.

Brito Neves, B. B. (1975). Regionalização geotectônica do Pré-Cambriano nordestino. Tese (Doutorado). São Paulo: Instituto de Geociências - USP.

Brito Neves, B. B., Kawashita, K., Mello, E. Z. V. (1977). Estudo geocronológico do Grupo Estância pelo Método Rb-Sr. VIII Simpósio de Geologia do Nordeste, Atas, 1, p. 311-322. Campina Grande: SBG, Núcleo Nordeste.

Condie, K. C. (1993). Chemical composition and evolution of the upper continental crust: contrasting results from surface samples and shales. Chemical Geology, 104(1-4), 1-37.

Davison, I., Santos, R. A. (1989). Tectonic evolution of the Sergipano Fold Belt, NE Brazil, during the Brasiliano Orogeny. Precambrian Research, 45(4), 319-342.

D'el-Rey Silva, L. J. H. (1992). Tectonic evolution of the southern part of the Sergipano fold belt, northeastern Brazil. Thesis (Doctorate). Londres: Royal Hollowal University London. 258p.

D'el-Rey Silva, L. J. H. (1994). The Sergipano Fold Belt and Implications for Proterozoic Tectonics. XXXVIII Congresso Brasileiro de Geologia, Boletim de Resumos Expandidos, 1, 265-267. Camboriú: SBG.
D'el-Rey Silva, L. J. H. (1995). The evolution of basement gneiss domes of the Sergipano fold belt (NE Brazil) and its importance for the analysis of Proterozoic basins. Journal of South American Earth Sciences, 8 (3/4), 325-340.

D’el-Rey Silva, L. J. H. (1999). Basin infilling in the southern-central part of the Sergipano Belt, NE Brazil, and implications for the tectonic evolution of the Pan-African/ Brasiliano cratons and Neoproterozoic sedimentary cover. Journal of South American Earth Sciences, 12(5), 453-470.

Farina, F., Albert, C., Lana, C. (2015). The Neoarchean transition between medium- and high-K granitoids: clues from the Southern São Francisco Craton (Brazil). Precambrian Research, 266, 375-394.

GEOTERM-NE. (2010). Geração de calor nas bacias de Cumuruxatiba, Jequitinhonha, Sergipe-Alagoas e Pernambuco-Paraíba, e nos embasamentos a elas adjacentes: relatório técnico de projeto. Bahia: Promob-Cenpes-Petrobras; CPGG-UFBA.

Harker, A. (1909). The natural history of igneous rocks. Nova York: Cambridge. 384p.

Humphrey, F. L., Allard, G. O. (1969). Geologia do Domo de Itabaiana (Sergipe) e sua relação com a geologia do geosinclinal de Propriá: um elemento tectônico recém reconhecido no escudo brasileiro. Rio de Janeiro: Petrobras/ CENPES. 104p.

Jackson, S. E., Pearson, N. J., Griffin, W. L., Belousova, E. A. (2004). The application of laser ablation-inductively coupled plasma-mass spectrometry to in situ U-Pb zircon geochronology. Chemical Geology, 211, 47-69.

Janoušek, V., Farrow, C. M., Erban, V., Trubač, J. (2011). Brand new Geochemical Data Toolkit (GCDkit 3.0) - is it worth upgrading and browsing documentation? (Yes!). Geologicke vyzkumy na Morave a ve Slezsku, 18, 26-30.

Ludwig, K. R. (2003). Isoplot 3.00. A geochronological toolkit for Microsoft Excel. Berkeley Geochronological Center, Special Publication, 4, 70.

Martin, H. (1993). The mechanisms of petrogenesis of the Archaean continental crust-comparison with modern processes. Lithos, 30, 373-388.

Martin, H. (1994). The Archean grey gneisses and the genesis of the continental crust. In: K. C. Condie (Ed.), Archean Crustal Evolution (205-259). Amsterdã: Elsevier. 
Martin, H., Smithies, R. H., Rapp, R., Moyen, J.-F., Champion, D. (2005). An overview of adakite, tonalite-trondhjemitegranodiorite (TTG), and sanukitoid: relationships and some implications for crustal evolution. Lithos, 79(1), 1-24.

Moyen, J.-F., Martin, H. (2012). Forty years of TTG research. Lithos, 148, 312-336.

O’Connor, J. T. (1965). A classification for quartz rich igneous rock based on feldspar rations. U. S. Geological Survey Professional Paper, 525B, 79-84.

Oliveira, E. P., McNaughton, N. J. Windley, B. F., Carvalho, M. J., Nascimento, R. S. (2015). Detrital zircon U-Pb geochronology and whole-rock Nd-isotope constraints on sediment provenance in the Neoproterozoic Sergipano orogen, Brazil: From early passive margins to late foreland basins. Tectonophysics, 662, 183-194.

Oliveira, E. P., Toteu, S. F., Araújo, M. N. C., Carvalho, M. J., Nascimento, R. S., Bueno, J. F., McNaughton, N., Basillici, G. (2006). Geologic correlation between the Neoproterozoic Sergipano belt (NE Brazil) and the Yaoundé belt (Cameroon, Africa). Journal of African Earth Sciences, 44, 470-478.

Oliveira, E. P., Windley, B. F., Araújo, M. N. C. (2010). The Neoproterozoic Sergipano orogenic belt, NE Brazil: a complete plate tectonic cycle in western Gondwana. Precambrian Research, 181(1), 64-84.

Pearce, J., Harris, N. B. W., Tindle, A. D. (1984). Trace element discrimination diagrams for the tectonic interpretation of granitic rocks. Journal of Petrology, 25, 956-983.

Peccerillo, A., Taylor, S. R. (1976). Geochemistry of eocene calc-alkaline volcanic rocks from the Kastamonu area, northern Turkey. Contributions to Mineralogy and Petrology, 58, 63-81.

Santiago, R. C. V. (2014). Petrografia e litogeoquímica dos ortognaisses migmatíticos do Domo de Itabaiana-SE. Trabalho Final (Graduação). Salvador: Instituto de Geociências-UFBA. 70p.

Santos, R. A., Martins, A. A. M., Neves, J. P., Leal, R. A. (1998). Programa Levantamentos Geológicos Básicos do Brasil (PLGB). Geologia e Recursos Minerais do Estado de Sergipe. Escala 1:250.000. Texto explicativo do mapa geológico do estado de Sergipe. Brasília: CPRM/DIEDIG/ DEPAT; CODISE. 156p.

Santos, R. A., Menezes Filho, N. R., Souza, J. D. (1988). Programa Levantamentos Geológicos Básicos: carta geológica, carta metalogenética/previsional. Escala 1:100.000, Projeto Carira, (4 v.). Brasília: DNPM/CPRM.
Shand, S. J. (1943). Eruptive rocks: their genesis, composition, and classification, with a chapter on meteorites. 2. ed. Londres: T. Murby \& co. 444p.

Siivola, J., Schmid, R. A. (2007). 12. List of mineral abbreviations. Recommendations by the IUGS Subcommission on the Systematics of Metamorphic Rocks. Disponível em: $<$ https://www.bgs.ac.uk/scmr/docs/papers/paper_12.pdf $>$. Acesso em: 15 out. 2015.

Silva Filho, M. A., Bonfim, L. F. C., Santos, R. A. (1978). A geossinclinal sergipana: estrutura e evolução. XXX Congresso Brasileiro Geologia, p. 2464-2477. Recife: SGB.

Silva Filho, M. A. B., Brito Neves, B. B. (1979). O sistema de dobramentos sergipano no nordeste da Bahia. Geologia e Recursos Minerais da Bahia: Textos Básicos, p. 203-214.

Sláma, J., Košler, J., Condon, D. J., Crowley, J. L., Gerdes, A., Hanchar, J. M., Horstwood, M. S. A., Morris, G. A., Nasdala, L., Norberg, N., Schaltegger, U., Schoene, B., Tubrett, M. N., Whitehouse, M. J. (2008). Plešovice zircona new natural reference material for $\mathrm{U}-\mathrm{Pb}$ and $\mathrm{Hf}$ isotopic microanalysis Chemical Geology, 249, 1-35.

Stacey, J. S., Kramers, J. D. (1975). Approximation of terrestrial lead isotope evolution by a two-stage model. Earth and Planetary Science Letters, 26, 207-221.

Streckeisen, A. (1976). To each plutonic rock its proper name. Earth-Science Reviews, 12(1), 1-33.

Takenaka, L., Lana, C., Scholz, R., Nalini Jr., H. A., Abreu, A. T. (2015). Optimization of the in-situ U-Pb age dating method via LA-Quadrupole-ICP-MS with applications to the timing of U-Zr-Mo mineralization in the Poços de Caldas Alkaline Complex, SE, Brazil. Journal of South American Earth Sciences, 62, 70-79.

Van Achterberg, E., Ryan, C. G., Jackson, S. E., Griffin, W. L. (2001). Data reduction software for LA-ICP-MS. Laser Ablation ICP-MS in the Earth Science, 29, 239-243.

Vaz Guedes, E. M. (2016). Esboço da zoneografia metamórfica do Subdomínio Macururé (Faixa Sergipana) nos estados de Sergipe e Alagoas. Trabalho Final (Graduação). Salvador: Instituto de Geociências - UFBA. 140p.

Wood, D. A., Joron, J.-L., Treuil, M. A. (1979). Re-appraisal of the use of trace elements to classify and discriminate between magma series erupted in different tectonic settings. Earth and Planetary Science Letters, 45, 326-336. 